\title{
Conceptual Approaches to Wellbeing in Buildings: A Scoping
}

Review

Madalina Hanc*

UCL Institute for Environmental Design and Engineering, University College London,

Central House, 14 Upper Woburn Place, London WC1H 0NN UK. Email:

m.hanc.12@ucl.ac.uk

Claire McAndrew

The Bartlett School of Architecture, University College London

22 Gordon St, London WC1H 0AJ. Email: c.mcandrew@ucl.ac.uk

Marcella Ucci

UCL Institute for Environmental Design and Engineering, University College London

Central House, 14 Upper Woburn Place, London WC1H 0NN UK. Email:

m.ucci@ucl.ac.uk

*Corresponding author

Acknowledgements, Funding and Disclosure

No funds were directly received for this research. Madalina Hanc was awarded an industryfunded scholarship from Cushman and Wakefield, Royal Bank of Scotland, British Land and CoreNet Global, whose contribution is gratefully acknowledged. Authors declare no conflict of interest. 


\section{Abstract}

Several industry-led initiatives in various countries demonstrate a new interest in wellbeing and buildings. This paper adopts a scoping review method aiming to establish the most prevalent and insightful definitions and dimensions of wellbeing in buildings applied in the recent published literature. The paper adopts a two-step method for identifying and categorising the conceptual approaches to wellbeing encountered in the current literature. First, the paper presents an overview of the term 'wellbeing' and its development over time. Second, the broad wellbeing categories identified are further refined and complemented via a deductive approach, drawing the final set of conceptual themes informed by the papers reviewed in this study. Nine themes were identified, two of which deductively emerged from the papers included in this study: environmental satisfaction/comfort and cognitive performance/productivity. The findings emphasise the heterogeneity of conceptual approaches to research concerning 'wellbeing in buildings', an ambiguity between wellbeing outcomes or determinants, and the need for greater clarity on the relative contributions of different wellbeing dimensions to overall individual or population wellbeing. Based on these findings, future work could be carried out to provide guidance on how to evaluate claims of evidence-based building design which foster individual or population wellbeing.

Keywords: wellbeing; buildings; built environment; scoping review 


\subsection{Introduction}

In recent years, several industry-led initiatives have signalled a new interest in the health and wellbeing agenda within the building sector. Amongst the most notable initiatives are the rise of new building certification systems focusing exclusively on health and wellbeing, as well as a series of well-received reports from the World Green Building Council (WGBC). The first of such reports was aptly titled 'Health, Wellbeing and Productivity in Offices: The Next Chapter for Green Building' (WGBC 2014). It captured the attention of many professionals, by arguing that one can make a compelling business case for green buildings, based not only on environmental and energy saving, but also on the potentially larger savings accrued on the biggest costs any organisation face: people. The success of the report is evidenced by further Green Building Council(s) (GBC) initiatives around the topic, including: the campaign 'Better Places for People' (WGBC 2016a); further reports addressing other building types - e.g. retail (WGBC 2016b) or homes (UK Green Building Council (UKGBC, 2016) - or providing evidence from case studies (UKGBC 2017a); and revenue-generating initiatives such as master classes and 'living labs' organised by country-specific sections of the WGBC, such as the UK's (UKGBC 2017b).

Besides the widely marketed initiatives of the $\operatorname{GBC}(\mathrm{s})$, the introduction of the equally prominent new certification system WELL Building Standard ${ }^{\mathrm{TM}}$ is a further milestone in the 'wellbeing in buildings revolution'. Launched in 2014, it claims to be: 
the premier standard for buildings, interior spaces and communities seeking to implement, validate and measure features that support and advance human health and wellness.

Other certification systems are also emerging, such as Fitwel, created as a joint initiative led by the US Centers for Disease Control and Prevention (CDC) and the General Services Administration (GSA), formally launched in 2017 after a fiveyear process. Despite its name, the discourse on Fitwel is more focused on 'health promotion', however the term 'wellness' is also liberally mentioned on their website (CDC 2018).

The initiatives mentioned above originate in the US, but have a large international reach, spanning across Europe and Asia. Country-specific initiatives are also abounding: for example, in April 2017, the British Council for Offices (BCO) announced the commissioning of a year-long study on: 'Wellness Matters: Health and Wellbeing in offices and what to do about it'. The UK's Building Research Establishment (BRE) has announced that their BRE office building is to become a 'living lab' for occupant health and wellbeing. It is notable that industry-led initiatives on building health and wellbeing are especially focused on the nondomestic commercial sector, whereas public health and policy efforts have traditionally focused on housing.

One of the interesting aspects of the initiatives discussed so far, besides their raisons d'être which is beyond the scope of this paper, is the frequent reference to 'health and wellbeing/wellness', used generally without accompanying definitions. This pairing seems to imply that 'health' and 'wellbeing' are distinct constructs. Yet, 
the well-known World Health Organisation (WHO) definition of health, which is included in its constitution adopted in 1946 (2006, 1), suggests:

Health is a state of complete physical, mental and social well-being and not merely the absence of disease or infirmity.

This definition suggests that 'health' is 'wellbeing'. The question therefore arises as to what is the particular role of 'wellbeing' within the context of buildings, and to what extent do academic endeavours in the published literature help shed light on this.

Despite the claims of 'evidence-based' approaches from the industry-led initiatives mentioned earlier, independent evaluations of such evidence and of the potential for fostering wellbeing via buildings is required. Evaluations conducted with the rigorous, bias-free methods adopted within the academia would surely validate - or reject - the robustness of such claims. Yet, crucially, this is not possible unless a mutually shared understanding and application of the term 'wellbeing' is identified. This is particularly important when considering that, as discussed in the next section, wellbeing is often conceived as a multi-dimensional construct which lends itself to a conveniently selective approach to prioritising such dimensions and hence the evidence underpinning it.

This paper is a review of the prevailing conceptual approaches to definition(s) of 'wellbeing' presented in the academic literature within the context of buildings. The study aims to identify the most prevalent and insightful definitions and dimensions of wellbeing (in buildings) applied in the recent published literature. 
Additionally, the paper hopes to initiate reflection on possible ways of evaluating claims of building design(s) which foster wellbeing.

The paper adopts a two-step method for identifying and categorising the conceptual approaches to wellbeing encountered in the current literature. It begins with an overview of the term 'wellbeing' and its development over time (section 2), as a means to guide initial efforts in the screening and categorisation of papers, and establish the extent to which, building-related research builds upon mainstream definitions of wellbeing. The broad wellbeing categories identified are further refined and complemented via a deductive approach, drawing the final set of conceptual themes informed by the papers reviewed in this study. The criteria for inclusion and exclusion, alongside the search strategy are described in section 3 .

\subsection{The Complex Nature of 'Wellbeing': Conceptual Origins and Definitions}

Colloquially referred to as 'happiness', wellbeing may have additional meanings. Definitions such as those from the Oxford English Dictionary (2016a,b) add complexity over clarity:

Well-being, $n$

With reference to a person or community: the state of being healthy, happy, or prosperous; physical, psychological, or moral welfare. With reference to a thing: good or safe condition, ability to flourish or prosper. In pl. Individual instances of personal welfare.

Add to this the synonym of 'wellness' and definitions become more obscure: 
Wellness, $\mathrm{n}$

The state or condition of being well or in good health, in contrast to being ill; the absence of sickness; the state of (full or temporary) recovery from illness or injury. spec. (orig. U.S.). As a positive rather than contrastive quality: the state or condition of being in good physical, mental, and spiritual health, esp. as an actively pursued goal; well-being.

The discourse surrounding 'wellness' positions the state of being 'well' both antithetically to ill-being, and as a "positive rather than contrastive" state of optimal functioning. On this issue, Huppert and So (2013) have maintained that "We need to study flourishing in its own right and not as the mere absence of mental disorder" suggesting it is not enough to '...tacitly assume[d] that well-being would prevail when pathology was absent' (p. 838).

Inherently 'slippery' and 'intangible', the multi-dimensional nature of this construct has produced 'blurred and overly broad definitions of wellbeing' (Forgeard, Jayawickreme, Kern and Seligman 2011, p. 81). Accordingly, there has been a tendency within the academe to concentrate on dimensions or descriptions as a means to express its nature (Christopher 1999; Dodge, Daly, Huyton and Sanders 2012). This has also translated into a variety of measurement approaches (beyond the scope of this paper, but for such discussions see: Gasper 2005; Huppert 2017). With no unified or accepted definition, this review makes reference to both descriptions and dimensions of wellbeing.

A variety of fields have, over time, been invoked in the task of defining wellbeing with psychology, sociology and economics, each representing a substantial cornerstone of this dialogue. The next sections touch upon the conceptual origins of 
wellbeing and the ways in which contemporary academic discourse from psychology to sociology and economics have strived (or more aptly, struggled) to provide definition (see Table 1 for a summary of key perspectives reviewed in this paper).

Table 1. Key psychological, sociological and economic approaches to wellbeing

\begin{tabular}{lll}
\hline \hline Psychological & Sociological & Economic \\
Hedonic (subjective wellbeing) & Negative subjective states & Capabilities \\
Eudaimonic & Positive social health & Social capital \\
Equilibrium (challenges/resources) & & Microeconomics \\
Flourishing or optimal functioning & & \\
\hline \hline
\end{tabular}

\subsection{Psychological perspectives: From Aristotle and the pursuit of pleasure, to flourishing}

Human potential - our natural desire to flourish and self-actualise - as a matter of wellbeing, extends back to Aristotle. As a philosophy, he considered hedonic 'happiness to be a vulgar ideal' preferring eudaimonic wellbeing as the ultimate state of human potential (Ryan \& Deci, 2001, p. 145). Hedonism uses 'happiness' as a proxy for wellbeing, defining it as the ultimate pursuit of pleasure and avoidance of pain (Kahneman, Diener, \& Schwartz, 1999). It is a tradition that has made use of the term 'subjective wellbeing' (a synonym often used interchangeably with hedonic wellbeing or in colloquial terms 'happiness'), comprising the measures of life satisfaction, pleasant and unpleasant affect (Diener and Suh 1997). 'Affect' is defined as a mental state, mood, or emotion, and 'life satisfaction' as a vehicle for understanding cognitive judgments associated with one's existence. An excess of positive over negative affect is construed as happiness or high psychological wellbeing, with low psychological wellbeing reflective the opposite. 
The hedonic pursuit of pleasure has become a topic of serious philosophical debate (Ryan \& Deci, 2001), with a critical eye cast on the basic validity of subjective wellbeing measures (Ryff \& Singer, 1998). If as Ryan and Huta (2009) speculate, subjective wellbeing were the only indicator of wellness, one would expect any increase in 'happiness' to produce a concomitant amount of 'wellness', which fails not only to account for the source of happiness but also the functioning of the individual.

The eudaimonic tradition on the other hand, considers wellbeing to be much more than happiness, in fact early work suggested it to be categorically distinct. Taking its meaning from daimon (one's true nature) the eudaimonic approach lies in the actualisation of human potential, with wellbeing seen as 'a complex construct that concerns optimal experience and functioning' (Ryan \& Deci, 2001, p. 141). It opens the possibility that not all desires, if satisfied will bring into being a sense of wellness.

Using self-determination theory to understand what it means to self-actualise, Ryan and Deci (2001) set forth three basic psychological needs: autonomy, competence and relatedness. Fulfilment of these needs is essential for psychological health and life satisfaction, not only defining the minimum requirements, but in prescribing elements of the social environment necessary to grow and thrive psychologically. However, self-determination theory views these as elements that foster wellbeing as opposed to being the building blocks of their definition (Ryff \& Singer, 1998). 
In their article titled 'The challenge of defining wellbeing', Dodge, Daly, Huyton, \& Sanders (2012) look back to Reber (1995) and suggest that rather than viewing wellbeing as a construct it ought to be considered a state, in Reber's words 'a condition of a system in which the essential qualities are relatively stable' (p. 750). Building upon Headey and Wearing's (1989) ‘dynamic equilibrium theory’, Dodge, Daly, Huyton, \& Sanders (2012) offer an alternative definition of wellbeing 'as the balance point between an individual's resource pool and the challenges faced' ( $p$. 230).

The most prevalent approach now is to view wellbeing as a multi-dimensional construct (Diener, 2009; Michaelson, Abdallah, Steuer, Thompson, \& Marks, 2009; Stigliz, Sen, \& Fitoussi, 2009). The emergence of the term 'flourish' (used synonymously with optimal functioning) is reflective of this movement (see for instance, Gable \& Haidt, 2005). In his book 'Flourish: A New Understanding of Happiness and Wellbeing', Seligman (2011) continues this shift in the conflation of these two notions. Building upon 'Authentic Happiness' theory (Seligman, Parks, \& Steen, 2004) and positive psychology, Seligman's approach could be aligned to 'wellness' as defined earlier: i.e. turning away from preventing or ameliorating 'mental illness' and 'negative states', but rather striving to capture the complex nature of human flourishing — the pleasure associated with hedonia and engagement connected with eudaimonia - through positive emotion, engagement, relationships, meaning and accomplishment. 


\subsection{Sociological contributions: The complexity of scaling up}

Although 'social wellbeing' is a key aspect in the WHO definition of 'health' (cited earlier), sociological contributions are rather scant. In an extensive review on the sociological contributions to subjective wellbeing, it has been remarked that:

Sociologists have not given much thought on this topic as yet, and mainstream opinion is still largely guided by the tale of the Brave New World (Huxley, 1932), in which subjective well-being goes hand in hand with superficial consumerism, political apathy, and general ignorance. (Veenhoven 2008, p. 11)

Anomie, deprivation, alienation and subjective poverty, are in the eyes of Veenhoven concepts indicative of sociology's almost exclusive focus on problems and negative subjective states. Some of the most notable sociological thinking has simultaneously cast its gaze back to psychology and forth to sociological theory. Defining social wellbeing as 'the appraisal of one's circumstance and functioning in society', Keyes (1998, p. 122) proposed five dimensions underscoring a global definition of social wellbeing: social integration, social contribution, social coherence, social actualisation and social acceptance. This has been subject to critique:

Such concepts cannot be meaningfully applied in a utilitarian search for social conditions that produce the greatest happiness for the greatest number. Applied for that purpose, such concepts lead to circular reasoning. If for example, we define subjective wellbeing as the feeling of connectedness that accompanies social integration, social integration is, by definition, a condition for subjective wellbeing. (Veenhoven 2008, p. 2). 
Some — like Cory Keyes — have cautioned at sociologists absolute rejection of psychological assumptions. A view that endures a decade later, Ruut Veenhoven (2008) finds relevance in social constructionism for subjective wellbeing — the idea that reality is constructed between/among social agents; and that a sociology of knowledge ought to reveal these processes (see Berger and Luckman 1966 for a full exposition). He argues we might see subjective wellbeing as a cognitive construct produced and (re)produced by collective assumptions of the 'good life'. This position is echoed by Cieslik (2015) who, returning to the works of Aristotle, remarks: '... ancient thinkers viewed happiness as a far more social phenomenon, co-produced and collective rather than the individualised notion we see today' (p. 426).

The notion of social capital is a commonly adopted construct used for the measurement of social wellbeing (Larson 1992; McDowell \& Newell 1987). Social capital derives value from personal relationships, social network support, civic engagement and cooperative norms (Siegler, 2015). Diener and Seligman's (2004) paper Beyond Money Toward an Economy of Wellbeing, notes that 'Supportive, positive social relationships are necessary for well-being. There are data suggesting that well-being leads to good social relationships and does not merely follow from them.' (1). Some consider social capital as a dimension of wellbeing, others see it as a determinant linked to subjective wellbeing through the channels of marriage, family, connections to friends, neighbours and work colleagues, civic engagement, trustworthiness and trust. These are, Helliwell and Putnam (2004) suggest, independently and robustly related to happiness and satisfaction through direct/indirect pathways to health. 
Within the context of this paper, it is important to emphasise that 'social wellbeing' can be considered intrinsically linked to 'personal' wellbeing: we need others to thrive, and we need to feel well in ourselves to be able to connect with others. On the other hand, various approaches exist to define/measure wellbeing at the population level, which in turn include individual, social, environmental and economic dimensions/indicators. Some of these aspects are discussed further in the next section.

\subsection{Economists conversations: Flourishing capabilities?}

Economists have also made important contributions to the wellbeing debate, at the individual and societal level. This has also opened up discussions about the role of economics and material life in connection to wellbeing, which have otherwise not been considered from psychological and sociological perspectives.

Much of the conversation has been inspired by the economist Amartya Sen's (1999) capability theory. Sen claims that wellbeing can be assessed by understanding individual's capabilities to do or be something and that individuals should be evaluated within the context of available opportunities, not their achievements. These valuable functionings are the essence of flourishing lives. 'Quality of life' is used synonymously with wellbeing, proposing 'wellbeing freedom' as the concept for assessment.

The New Economics Foundation (NEF) (2012) has been at the forefront of such work, bridging hedonic elements of wellbeing with economists' thoughts on capabilities. Although acknowledging that wellbeing extends beyond 'happy 
feelings', the NEF suggests that positive feelings such as 'happiness' can provide a vehicle for improved wellbeing overall, building personal resources and capabilities, to enable positive responses in moments of challenge. The NEF makes a distinction between the 'emotions, judgements and experiences' of wellbeing, internal drivers (health, optimism and self-esteem), and external drivers (income, housing, education and social networks), suggesting it is their interaction that enables individual functioning and the experience of positive emotions, which provide the precondition for 'flourishing'.

The ONS roots UK national wellbeing in the concept of social capital. Through analogy to its binding properties, it is often described as 'the glue that holds societies together and without which there can be no economic growth or human well-being' (World Bank, 1998, p. ii). Similarly, the United Nations Development Programme (UNDP) created the Human Development Index (HDI) based on the idea that economic growth alone is an insufficient indicator for assessing the development of a country. Instead, HDI is 'a summary measure of average achievement in key dimensions of human development: a long and healthy life, being knowledgeable and have a decent standard of living' (UNDP, nd). Richard Layard (2005) proposes that any notion of a 'good society' ought to bridge objective/subjective characterisations of wellbeing, in addition to economic growth and material prosperity. Quoting the Chairman of the US Federal Reserve, Layard, Clark, Cornaglia, Powdthavee, \& Vernoit (2013) state: 'The ultimate purpose of economics, of course, is to understand and promote the enhancement of well-being' (1). Economics takes a vividly different approach to definition than psychology and sociology. It is more sensitive to context 
and pluralistic in orientation, acknowledging the role and importance of material and nonmaterial life (Cronin de Chavez, Backett-Milburn, Parry, \& Platt (2005). One of the advantages of economic indicators are their external validity, but their internal validity — that is whether they truly represent quality of life at the societal level — is more uncertain. As Diener and Seligman (2004) have noted 'Domestic policy currently focuses heavily on economic outcomes, although economic indicators omit, and even mislead about, much of what society values' (1). Citing the general trend for growth in economic output over the last few decades, they note the failure to see a concomitant increase in life satisfaction. This is complex, when economic indicators are fundamental in the early stages of economic development for the fulfillment of basic human needs.

At the same time, in microeconomics larger pools of choice are assumed to correlate with a higher quality of life, as individuals make decisions to maximise their wellbeing (see Kahneman 2003). Correlated closely with available choice, income has also been equated with higher levels of wellbeing, driving the use of income as a proxy.

One challenge for a society based on well-being is that individuals do not have ready and concrete models of how to pursue the goal of greater well-being, other than following the economic model. When people are asked what would improve the quality of their lives, the most frequent response is higher income (Campbell, 1981). It is not clear to people how they would achieve greater positive emotions and life satisfaction. Until there are concrete and proven steps toward these noneconomic aims, people are unlikely to abandon the dominant economic paradigm. (Diener \& Seligman, 2004, p. 25) 
The thumbnail sketch provided in this section demonstrates what Pollard and Lee describe as a 'confusing and contradictory research base' (2003, p. 2). The key conversations within psychology, sociology and economists commentaries, illustrate both the breadth of contributions and difficulty of definition (see Table 1 for a summary). When these discussions concern the built environment, additional layers of complexity may be added to the equation. The following sections explore some of the ways in which buildings are believed to contribute to wellbeing.

\subsection{Methods}

\subsection{General framework}

A scoping review method was adopted, an approach commonly used to examine the extent and nature of research activity in a topic area, summarise findings and identify research gaps in the existing literature (Pham et al. 2014). Similar to systematic reviews, they use rigorous and transparent methods allowing replicability, however they do not typically include quality assessments of the available literature (Grant \& Booth 2009). This review followed the broad process described by Levac, Colquhoun, \& O'Brien (2010): identifying the research question; identifying relevant studies; study selection; charting the data; and collating, summarising and reporting the results. The optional stakeholder consultation was not carried out.

\subsection{Research question and search criteria}

This scoping review was guided by the research question: 'How is wellbeing conceptualised in building-related research?'. The paper aims to establish the most 
prevalent and insightful definitions and dimensions of wellbeing in buildings applied in the recent published literature. It therefore seeks to explore:

- What key themes or concepts are commonly discussed ('prevalent');

- How are these themes and concepts defined and operationalised ('insightful').

Informed by the literature review, the paper includes articles discussing wellbeing from psychological, sociological and economic perspectives, and other dimensions. Given our focus on 'wellbeing', and the vast amount of literature published in public health and epidemiology journals where 'health and wellbeing' are often referred to mainly examine disease and 'ill-health', papers on clinically diagnosable psychiatric or health conditions had to be excluded, in order to maintain a suitably manageable focus. The exclusion criteria are described further in section 3.4. The review includes articles published over a ten year period (from January 2005 to June 2016).

Since buildings are not isolated artefacts within the built environment, research pertaining to notions of 'neighbourhoods', 'place' and the 'built environment' were also reviewed as a part of this process. However, the emphasis of this analysis was placed on the notion of 'buildings', and therefore papers focusing on other scales were excluded if not considered relevant to this dimension. 


\subsection{Database search and screening process}

The Scopus database of citations and abstracts of peer-reviewed literature (Elsevier, 2018) was used to perform searches using AND/OR Boolean operators, filtering results according to subject area.

In the Identification phase, two types of initial searches were performed (steps 1 and 2):

(1) General Scopus search: 'Well-being' or 'wellbeing' in the article title, searched for in combination with the terms 'buildings', 'neighbourhoods', 'places' and 'built environment' in the article title, abstract, or key words.

(2) Journal-specific searches within Scopus: As above, across seven journals considered relevant by the authors: Architectural Science Review, Building and Environment, Building Research and Information, Environment and Behaviour, Health and Place, Indoor and Built Environment, and International Journal of Qualitative Studies on Health and Well-being.

Arguably due to the breadth of research captured by the word 'place', many articles from the initial 'wellbeing' and 'place' subset appeared out of scope. A first screening by subject area was performed at this stage. These results were filtered by limiting the subject area to: Social Sciences, Psychology, Environmental Science, Arts and Humanities, and Business, Management and Accounting; and use of keywords such as: quality of life, mental health, happiness, psychological aspect, urban area, landscape, and neighbourhood characteristics. The articles were clustered according to scale (i.e. building, neighbourhood, place and built environment). 
In the Screening phase, results from both search types were collated (step 3), removing all duplicates (step 4). The papers' potential relevance for this review was initially assessed based on their titles (step 5) and - for the remaining papers - on their abstracts (step 6). The latter step explored whether the abstracts described wellbeing approaches similar to those outlined in Table 1, or any other clearly stated approaches. Uniqueness of content was also considered - occasionally the same study was presented in several papers. After downloading the full-text version of the articles included up to that point (step 7), the initial clustering of articles according to scale (as retrieved from Scopus searches) i.e. 'buildings', 'neighbourhoods', 'places' or 'built environment' were reviewed. In some instances, articles from the general search were re-categorised. Articles retrieved from journal-specific searches were also integrated into these scales.

In the Review and reporting phase, papers were clustered by the conceptual themes illustrated in Table 1 (step 8). Those papers featuring themes not captured by the approaches outlined in Table 1 were assigned to the 'Other' category (or excluded, if out of scope) - unless substantial clustering emerged; if so, they were assigned thematic status. Finally, for each theme within the 'buildings' scale, subthemes were identified, refined and assigned (step 9). This final stage involves the analysis and discussion of the final themes/subthemes.

\subsection{Exclusion criteria}

Exclusion criteria were used by the authors to ensure the articles included were suited to the goals of our study, i.e. provided insightful definitions and 
conceptualisations of wellbeing in buildings. While some of these criteria were applied during the initial Scopus search (e.g. filtering articles via search terms in the title and abstract, publication type and date etc.), a small number of articles with no full-text availability or that were not peer-reviewed papers were excluded. The most common basis for exclusion related to irrelevant content for this review (i.e. the ways in which wellbeing was conceptualised) with examples including those with a sole focus on physical activity, physical or mental ill-health, or natural environments. Consequently, papers discussing wellbeing from the specific perspective of healthcare environments were generally excluded, unless they considered wellbeing for staff which was considered a focus on workplace environment.

Given the diverse nature of buildings in relation to the other dimensions of neighbourhood, place or built environment, papers within these categories were included only if their focus primarily addressed aspects of the physical environment (as opposed to the social environment) which were more directly relevant to buildings (e.g. papers exclusively focusing on transport for example were excluded). Papers focusing exclusively on the wellbeing impact of nature, green or blue space, or restorative environments were excluded. A scoping review on this topic is already published (Bell, Foley, Houghton, Maddrell, \& Williams, 2018).

\subsection{Categorisation approach: Further details}

The development of the wellbeing themes was a two-way process informed by the definitions and concepts obtained from the earlier literature review, alongside themes and subthemes emerging from the papers identified in the scoping process. 
The summary of key psychological, sociological and economic approaches to wellbeing outlined in Table 1, was used to inform the set of definitions initially guiding the scoping review. The recognition of wellbeing as an inherently ambiguous and 'hard to define' concept, is evident in areas of overlap between psychological, sociological and economic approaches. This warranted some approaches to be included within others, for instance, negative subjective states within hedonic (as it considers subjective judgments of negative affect), and social capital within positive social health (social capital is regarded as one dimension of social wellbeing). With 'flourishing' spanning the breadth of hedonic and eudaimonic features, two sub-categories were developed to capture the diametric relation of optimal functioning to ill-being: mental health (including psychological distress such as anxiety and depression, and excluding those with a more enduring pathology) and physical health (capturing those elements that speak to physical illness and defect). It is acknowledged that a broad use of the term 'mental health' would include aspects pertaining affect and hedonic or even eudaimonic approaches. Whenever possible, papers were assigned to one or the other themes depending on information provided within the papers themselves. The definitions were also shaped in a ground-up manner by the scoping review. With no direct reference to wellbeing conceived as a state of 'equilibrium (challenges/resources)', 'capabilities' or 'microeconomics', these approaches to definition were omitted. The review did however, reveal a propensity within built environment research to conceive of wellbeing in relation to 'environment satisfaction / comfort' and 'productivity / cognitive performance' which 
were added to our list of definitions. Overall, nine themes were identified (for detailed description, see Table A.1 in Appendix):

- Hedonic or Subjective Wellbeing (HED)

- Eudaimonic Wellbeing (EUD)

- Social Wellbeing (SOC)

- Mental Health (MH)

- Physical Health (PH)

- Environmental Satisfaction and/or Comfort (ENV)

- Productivity and Cognitive Performance (PRO)

- Other $(\mathrm{O})$

- Unspecified (UN)

While this conceptualisation framework was a useful tool for this review, it is by no means exhaustive - as shown in the Introduction and Literature review, other conceptualisations of wellbeing are possible. Furthermore, in assigning these themes, no attempt was made to weigh the relative importance of each construct within the paper: some papers may have focused primarily on one of the dimensions, and only briefly mentioned the others; our analysis counted all of the constructs mentioned in the paper. Furthermore, some papers did not explicitly discuss the relative importance of dimensions, therefore an attempt to include this aspect in our review would not have been possible. 
Results obtained at various stages were recorded using Excel spreadsheets shared by the authors; comments and revisions were added to the document, and discussed regularly. The categorisation process was based on the authors' reading of the papers' titles, abstracts and - in later phases - full text without the aid of qualitative text analysis software. The decision not to use qualitative analysis software tools was dictated by a need to maintain the flexibility and transparency of the categorisation process, which operated with ambiguous terms (as shown above), and was often iterative.

\subsection{Results}

\subsection{Preliminary and revised results}

Figure 1 illustrates the entire process from initial paper searches to final paper selection. Of the 59 articles included in the review, 48 papers were retrieved from general searches, and 11 from specific journal searches: Architectural Science Review

- 1 article; Building and Environment - 2; Building Research and Information - 2;

Health and Place - 4; Indoor and Built Environment -2; no relevant results retrieved from the other two journals. Papers from some of these journals were also retrieved from general searches. 
Figure 1. Scoping review process

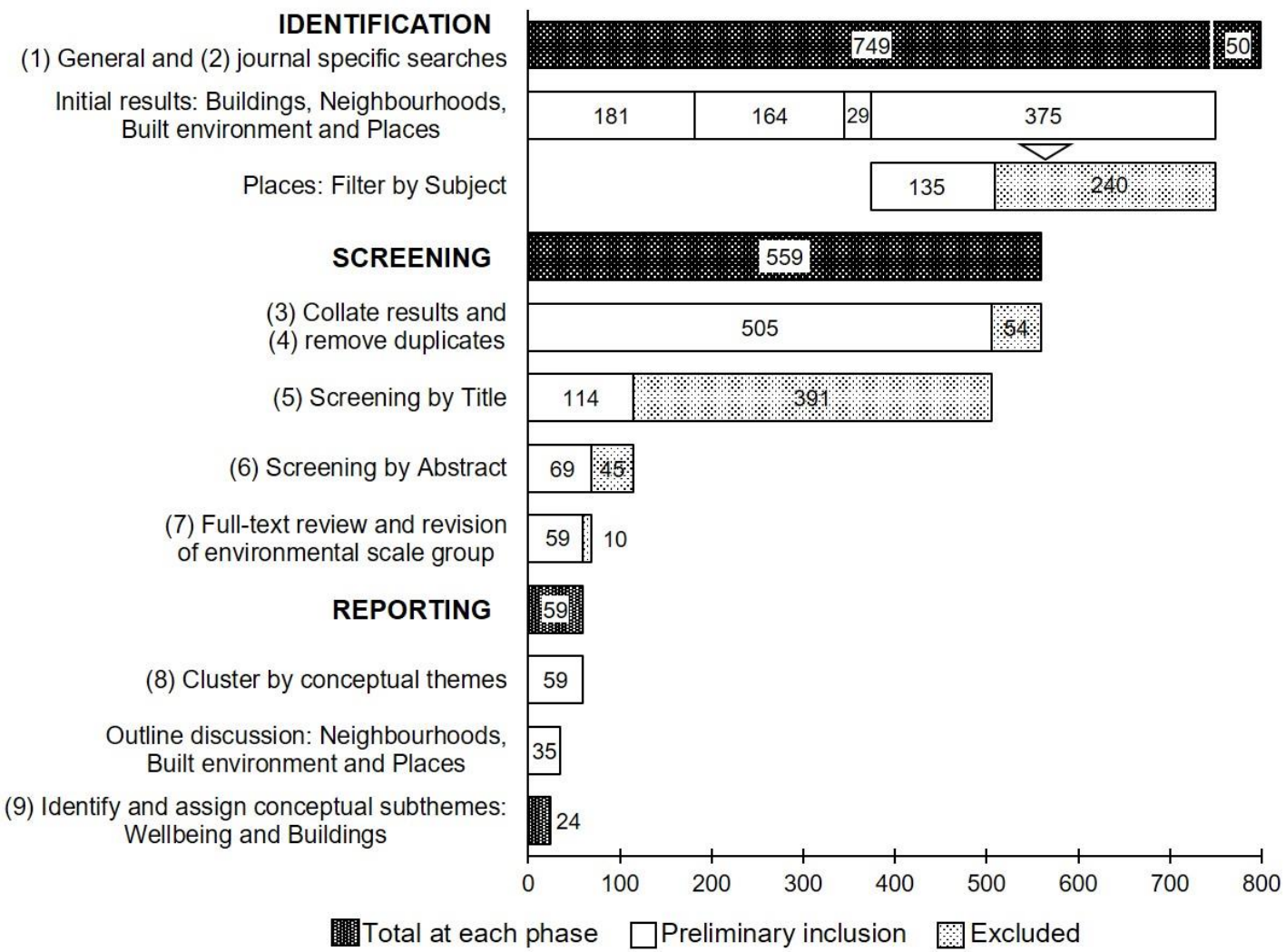

\subsection{Overview}

Table 2 shows how many papers, within each domain, address the various conceptual themes, and figure 2 illustrates the distribution of each theme within each domain. Since most papers touched upon several themes, the same paper may be used to populate the figures across each row. The full list of papers with their categories is provided in the Appendix.

Furthermore, table 2 shows that most of the articles across all four groups considered the theme 'Environmental Satisfaction and/or Comfort' (ENV, 42 papers), closely followed by 'Social Wellbeing' (SOC, 39) and 'Hedonic or Subjective Wellbeing' (HED, 36). Perhaps unsurprisingly, SOC was more common at the 
neighbourhood scale (18), than at the other scales. However, at the neighbourhood scale, 17 papers included instances of themes classified as Other (OT) - an indication perhaps of the heterogeneity of the papers within this scale, in relation to the conceptual approaches derived here. Wellbeing was also frequently considered to be a measure of 'Physical Health' (PH, 34), or considered to be related to 'Mental Health' (MH, 32). Fewer papers considered 'Eudaimonic' aspects of wellbeing (EUD, 15), or 'Productivity and Cognitive Performance' (PRO, 11). Apart from these categories, 29 papers also considered 'Other' interpretations of wellbeing (OT, 29), and six were classified as 'Unspecified' since they did not explicitly specify their perspective (UN, 6).

Table 2. Summary of results: Wellbeing conceptual themes and environmental scales.

Environmental scale

\begin{tabular}{llllllllll}
\hline & ENV & MH & PH & HED & EUD & SOC & PRO & O & U \\
\hline \hline Buildings (24 papers) & 21 & 11 & 15 & 16 & 6 & 11 & 8 & 5 & 3 \\
Neighbourhoods (24 papers) & 18 & 15 & 14 & 16 & 5 & 18 & 2 & 17 & 1 \\
Built Environment (5 papers) & 2 & 3 & 2 & 3 & 1 & 5 & 0 & 5 & 0 \\
Places (6 papers) & 1 & 3 & 3 & 1 & 3 & 5 & 1 & 2 & 2 \\
\hline Total $^{*}$ & 42 & 32 & 34 & 36 & 15 & 39 & 11 & 29 & 6
\end{tabular}

${ }^{*}$ Note: Numbers indicate how many papers mention a theme; most papers covered more than one theme. **Acronyms:

ENV: Environmental Quality, Satisfaction and/or Comfort; MH: Mental Health; PH: Physical Health; HED: Hedonic or Subjective Wellbeing; EUD: Eudaimonic Wellbeing; SOC: Social Wellbeing; PRO: Productivity and Cognitive Performance; O: Other; U: Unspecified. 
Figure 2. Wellbeing conceptual themes across environmental scales.

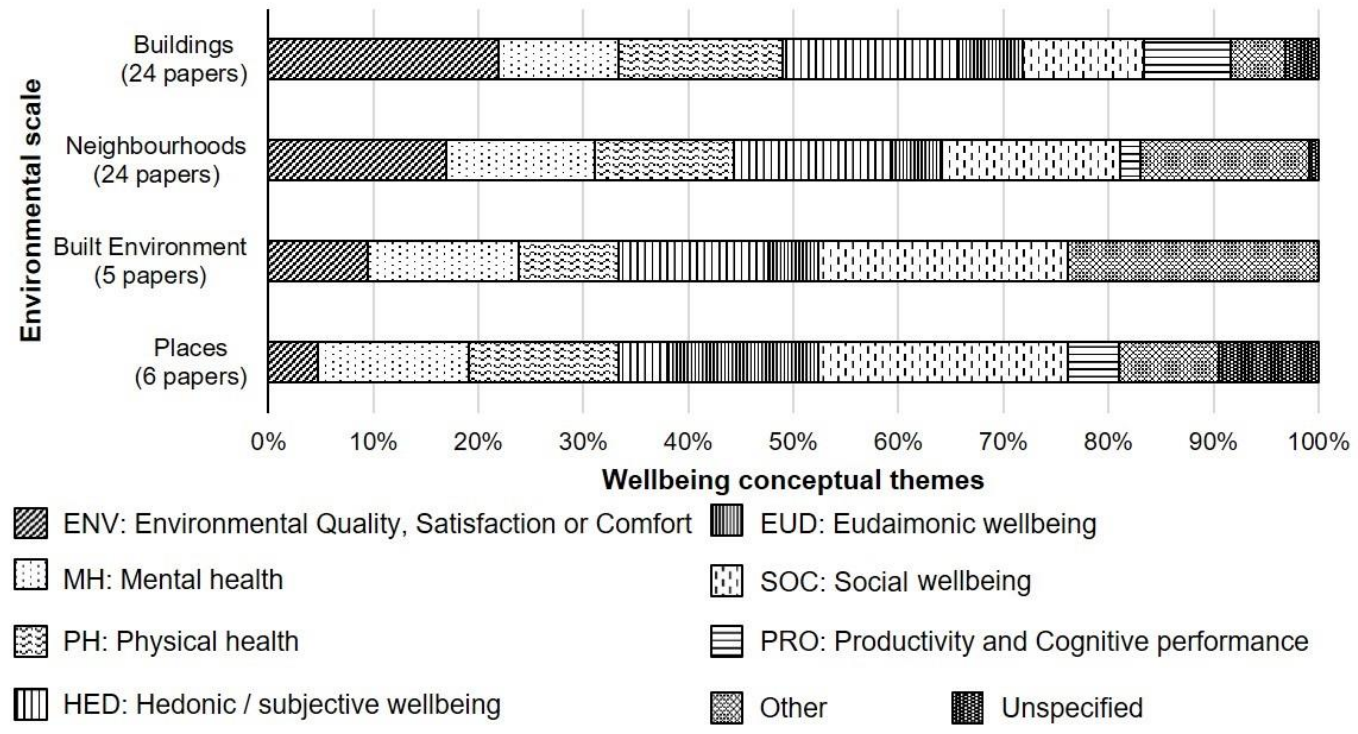

It was generally observed that the majority of the papers adopted complex and heterogeneous approaches to wellbeing, that included a few conceptual themes, as summarised in tables A.1 - A.2 (Appendix).

\subsection{Wellbeing and buildings: Conceptual themes and subthemes}

Of the 24 papers discussing wellbeing at Building level, 21 (or 88\%) considered the ENV theme. The second most common themes identified within the papers were HED (16 or 66\%), closely followed by HT (15, or 63\%) and MNT and SOC (11 papers, or $46 \%$ each). Fewer papers included wellbeing conceptualisations as PRO (8, or 33\%) and EUD (6 or $25 \%)$. Five papers (or $20 \%$ ) used 'Other' conceptual approaches and three (12\%) mentioned wellbeing without specifically stating how the concept had been operationalised (UN). Table 3 shows the conceptual themes assigned to each building-scale paper. A further categorisation using sub- 
themes was then performed, as illustrated in Figure 3. These findings are discussed further in the next section.

Table 3. Wellbeing and buildings: Conceptual themes

\begin{tabular}{|c|c|c|c|c|c|c|c|c|c|c|}
\hline \multirow[t]{2}{*}{ Paper citation } & \multicolumn{10}{|c|}{ Wellbeing conceptual themes used in the review* } \\
\hline & ENV & HED & $\mathrm{PH}$ & $\mathrm{MH}$ & SOC & PRO & EUD & $\mathrm{O}$ & $\mathrm{U}$ & Total \\
\hline $\begin{array}{l}\text { Alvaro, Wilkinson, Gallant, Kostovski, \& } \\
\text { Gardner (2016) }\end{array}$ & $X$ & $X$ & $x$ & $X$ & $x$ & & $X$ & $X$ & & 7 \\
\hline $\begin{array}{l}\text { Bluyssen, Janssen, Van den Brink, \& De } \\
\text { Kluizenaar (2011) }\end{array}$ & $\mathrm{X}$ & $\mathrm{X}$ & $\mathrm{X}$ & $X$ & $\mathrm{X}$ & & $\mathrm{X}$ & $\mathrm{X}$ & & 7 \\
\hline Thatcher \& Milner (2014) & $\mathrm{X}$ & $\mathrm{x}$ & $\mathrm{X}$ & & $\mathrm{X}$ & $\mathrm{X}$ & $\mathrm{X}$ & $\mathrm{X}$ & & 7 \\
\hline Lamb, Kwok, \& Walton (2014) & $\mathrm{X}$ & $\mathrm{X}$ & $\mathrm{X}$ & $\mathrm{X}$ & & $\mathrm{X}$ & $\mathrm{X}$ & & & 6 \\
\hline Shafaghat et al. (2014) & $\mathrm{X}$ & & $\mathrm{X}$ & $\mathrm{X}$ & $\mathrm{X}$ & & $\mathrm{X}$ & $\mathrm{X}$ & & 6 \\
\hline Torrington (2007) & $\mathrm{X}$ & $\mathrm{X}$ & $\mathrm{X}$ & $\mathrm{X}$ & $\mathrm{X}$ & & $\mathrm{x}$ & & & 6 \\
\hline Newsham et al (2009) & $\mathrm{x}$ & $\mathrm{x}$ & $\mathrm{X}$ & $\mathrm{X}$ & $\mathrm{x}$ & & & & & 5 \\
\hline Butala \& Muhič (2007) & $\mathrm{X}$ & $\mathrm{X}$ & $\mathrm{X}$ & $\mathrm{X}$ & & $\mathrm{X}$ & & & & 5 \\
\hline Fostervold \& Nersveen (2008) & $\mathrm{X}$ & $\mathrm{X}$ & $\mathrm{x}$ & $\mathrm{X}$ & & $\mathrm{X}$ & & & & 5 \\
\hline $\begin{array}{l}\text { Agha-Hossein, El-Jouzi, Elmualim, Ellis, \& } \\
\text { Williams (2013) }\end{array}$ & $\mathrm{x}$ & $\mathrm{X}$ & & & & $\mathrm{X}$ & & & $\mathrm{X}$ & 4 \\
\hline Denk, Jimenez, \& Schulz (2015) & $\mathrm{X}$ & $\mathrm{x}$ & & $\mathrm{X}$ & & $\mathrm{X}$ & & & & 4 \\
\hline $\begin{array}{l}\text { Tavakkoli, Asaadi, Pakpour, \& } \\
\text { Hajiaghababaei (2015) } \\
\end{array}$ & & $\mathrm{X}$ & $\mathrm{X}$ & $\mathrm{X}$ & & & & & $\mathrm{X}$ & 4 \\
\hline Turunen et al (2014) & $\mathrm{x}$ & & $\mathrm{X}$ & & & $\mathrm{X}$ & & & $\mathrm{X}$ & 4 \\
\hline Kang, Lee, Kim, \& Kim (2014) & $\mathrm{X}$ & & & & $\mathrm{X}$ & & & $\mathrm{X}$ & & 3 \\
\hline Muhammad, Sapri, \& Sipan (2014) & $\mathrm{X}$ & & & & $\mathrm{X}$ & $\mathrm{X}$ & & & & 3 \\
\hline$\underline{\text { Rioux (2005) }}$ & $\mathrm{x}$ & $\mathrm{x}$ & & & $\mathrm{X}$ & & & & & 3 \\
\hline Steemers \& Manchanda (2010) & $\mathrm{X}$ & $\mathrm{X}$ & $\mathrm{x}$ & & & & & & & 3 \\
\hline Wilson et al. (2014) & $\mathrm{X}$ & & $\mathrm{X}$ & $\mathrm{X}$ & & & & & & 3 \\
\hline Lee, Je, \& Byun (2011) & $\mathrm{X}$ & & $\mathrm{x}$ & & & & & & & 2 \\
\hline Neuner \& Seidel (2006) - & $x$ & $\mathrm{X}$ & & & & & & & & 2 \\
\hline Pelenur \& Cruickshank (2013) & $\mathrm{X}$ & $\mathrm{X}$ & & & & & & & & 2 \\
\hline Easterbrook \& Vignoles (2015) & & $\mathrm{X}$ & & & $\mathrm{x}$ & & & & & 2 \\
\hline Neuner \& Seidel (2006) & & & $\mathrm{X}$ & & & & & & & 1 \\
\hline Abell et al (2013) & & & & & $\mathrm{X}$ & & & & & 1 \\
\hline Wu \& Noy (2010) & $\mathrm{X}$ & & & & & & & & & 1 \\
\hline Total & 21 & 16 & 15 & 11 & 11 & 8 & 6 & 5 & 3 & 95 \\
\hline
\end{tabular}

*Acronyms:

ENV: Environmental Quality, Satisfaction and/or Comfort ; MH: Mental Health; PH: Physical Health; HED: Hedonic or Subjective Wellbeing; EUD: Eudaimonic Wellbeing; SOC: Social Wellbeing; PRO: Productivity and Cognitive Performance; O: Other; U: Unspecified. 
Figure 3. Wellbeing and Buildings scoping review results: Themes and subthemes

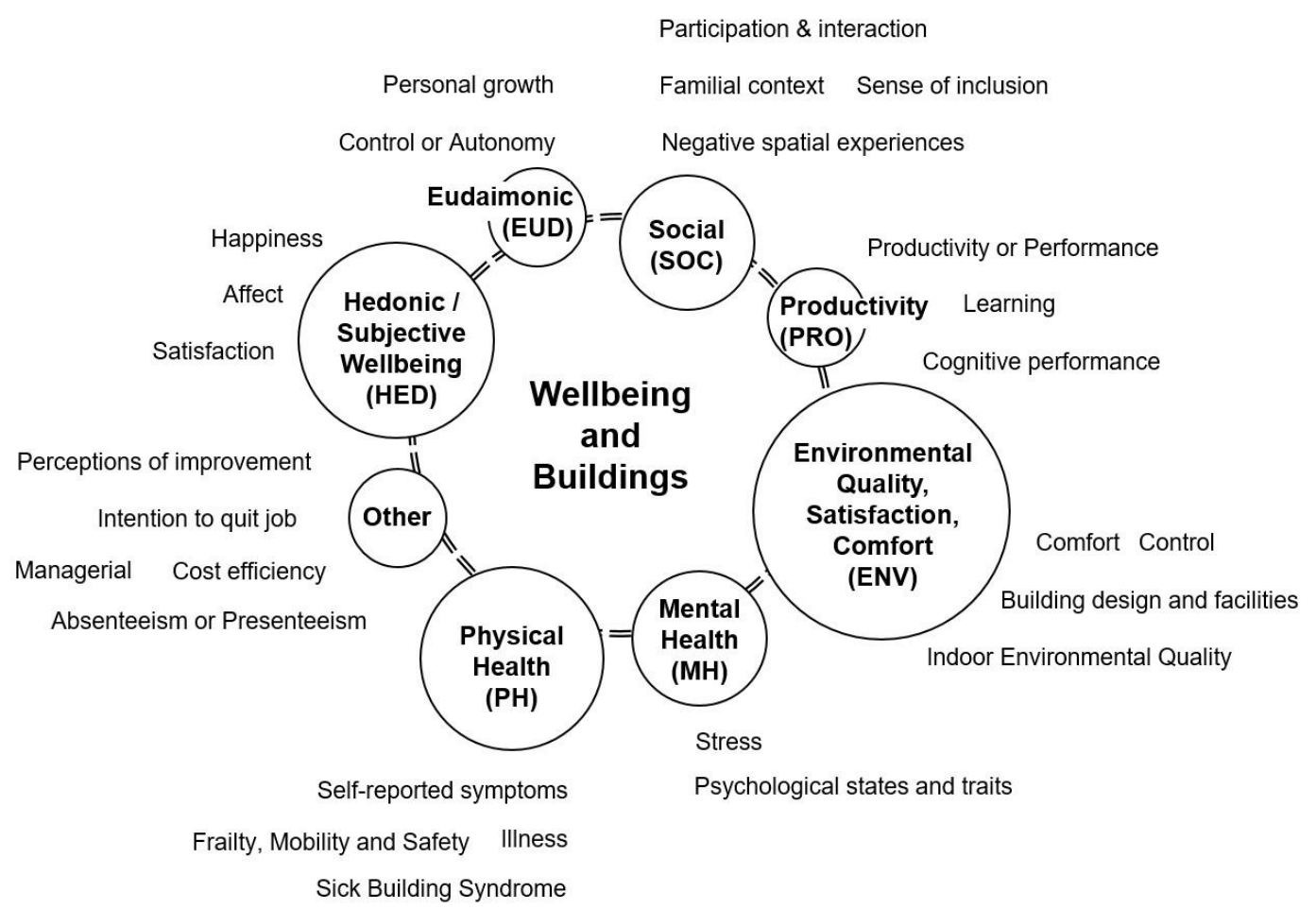

\subsubsection{Environmental Quality, Satisfaction and/or Comfort (ENV)}

A central subtheme identified within the dataset of papers that had used ENV was Indoor Environmental Quality (IEQ). Depending on the scope of each paper, IEQ referred to specific physical parameters including temperature, air quality, light and lighting, or noise (Newsham et al,. 2009; Steemers \& Manchanda, 2010; Wu \& Noy, 2010; Agha-Hossein, El-Jouzi, Elmualim, Ellis, \& Williams, 2013; Lamb, Kwok, \& Walton, 2014; Butala \& Muhic 2007; Turunen et al., 2013; Kang, Lee, Kim, \& Kim, 2014), and/or overall environmental satisfaction or comfort (Muhammad, Sapri, \& Sipan, 2014; Newsham et al., 2009). Building Design and $\underline{\text { Facilities }}$ was also identified as a subtheme; examples include aspects related to workstation furnishings and equipment (Newsham et al., 2009), or 'Characteristics of 
building, systems and rooms such as windows, view, services (heating, lighting systems),...,cleanliness' (Bluyssen, Janssen, Van den Brink, \& De Kluizenaar, 2011, p. 2637), or specific 'residential quality factors' such as the ecological environment, security and safety, or convenience and management (Lee, Je, \& Byun, 2011).

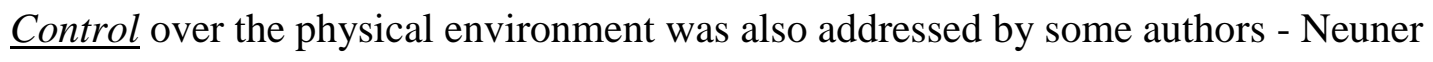
\& Seidel (2006, p. 370) including aspects of 'Influence on room temperature, Influence on ventilation, Influence on lighting' with respondents asked if they 'wish direct control of the indoor climate?'. While comfort or satisfaction were commonly used to measure or conceptualise aspects of IEQ, some authors conceptualised

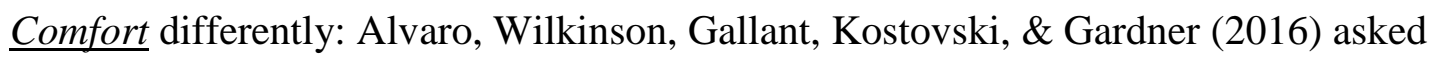
participants to rate 'the extent to which... they felt the hospital was not comforting versus comforting' (p. 86).

\subsubsection{Hedonic / Subjective wellbeing (HED)}

Many of the papers that included HED aspects of wellbeing considered aspects related to $\underline{\text { Affect }}$. Some authors adopted comprehensive approaches: Bluyssen et al. (2011) for instance considered emotions such as 'Worry, nervousness, fear...Anger, hostility and aggressiveness, Sadness,...,Happiness, satisfaction, joy, ecstasy' (p. 2637). Similarly, Butala \& Muhic (2007) used a comprehensive questionnaire 'composed of 47 items describing how people might feel' (p. 304). Denk, Jimenez, and Schulz (2015) used the Positive and Negative Affect Scale, and Torrington (2007) considered the Frequency and enjoyment of pleasant activities, and Outward signs of emotion. Other authors considered specific aspects of Affect, such as 'How do you think having an energy management system in your home will make 
you feel?' (Pelenur \& Cruickshank, 2013, p. 33), or mood (Lamb, Kwok, \& Walton, 2014). Satisfaction was also a common subtheme, with many authors investigating specific issues such as job satisfaction (Lamb et al., 2014; Steemers \& Manchanda, 2010; Tavakkoli, Asaadi, Pakpour, \& Hajiaghababaei, 2015; Thatcher \& Milner, 2014), organisational satisfaction (e.g. 'Satisfaction with employment compensation, Satisfaction with management', Newsham et al. 2009, p.146) or perceived enjoyment at work (Agha-Hossein et al. 2013). In some cases, there was an overlap of the HED, SOC and EUD dimensions of wellbeing, for instance Alvaro et al. (2016) considered Satisfaction with 'interaction with coworkers, resolution of conflict,..., communication within the organization, communication with supervisors, involvement in decision making' (p. 88). Similarly, Rioux's (2005) perspective on Life satisfaction included questions such as: 'In most ways my life is close to my ideal'; 'The conditions of my life are excellent'; 'So far I have gotten the important things in want in life'; 'If I could live my life over I could change almost nothing' (p. 234).

\subsubsection{Physical Health (PH)}

Within the papers that included the PH dimension, Self-reported symptoms were the most frequent sub-theme, which covered both non-specific symptoms such as headaches or fatigue as well as other symptoms including: musculoskeletal pains; eye, throat, nose or skin irritation; respiratory symptoms (e.g. Neuner \& Seidel, 2006; Fostervold \& Nersveen, 2008; Turunen et al., 2013). Another sub-theme was $\underline{\text { Ilness }}$, sometimes intended in a generic sense of ill-health (e.g. Thatcher \& Milner, 2014), but other times intended as specific underlying conditions or health outcomes (e.g. 
Bluyssen et al., 2011; Shafaghat et al., 2014). Some of these sub-themes appeared in conjunction with Sick Building Syndrome (e.g. Bluyssen et al., 2011; Neuner \& Seidel, 2006; Shafaghat et al., 2014; Thatcher \& Milner, 2014). The aforementioned sub-themes were covered especially in papers focusing on offices or schools, whereas a handful of papers which included residential environments (such as care homes) or hospitals also considered Frailty, Mobility or Safety. (Alvaro et al., 2016; Lee et al., 2011; Torrington, 2007).

\subsubsection{Mental Health (MH)}

The MH theme was commonly associated with $\underline{\text { Stress, }}$ in particular, aspects of job-related stress. Newsham et al. (2009) included dimensions concerning 'Selfreported stress associated with job Stress (stressful job, relaxing job), job fatigue, not enough time' (p. 146), while Alvaro et al. (2016) investigated workplace burnout; similarly, the Nursing Stress Scale was used by (Torrington, 2007) to assess nurses' morale. However, other authors simply referred to 'psychological stressors' (Shafaghat et al., 2014). Psychological states and traits were also used as ways of operationalising mental health. Wilson et al. (2014) included questions on how often participants had felt 'nervous, ,..,restless or fidgety,...hopeless, ... worthless' (p. 157) in the previous month. Similarly, anxiety and depression were often taken into account (Bluyssen et al. 2011; Fostervold \& Nersveen 2008; Alvaro et al. 2016). Some authors included measures that arguably overlap with HLT or SOC dimensions of wellbeing, for example Tavakkoli et al. (2015) included measures of anxiety and insomnia, severe depression, and social dysfunction. 


\subsubsection{Social (SOC)}

Within the papers that explored the SOC dimension of wellbeing, the most frequent subtheme was Participation and interaction. Easterbrook \& Vignoles's (2015) investigation of shared student accommodation included questions such as 'How often, on average, do you coincidentally bump into your flatmates in and around the flat?' or 'How much do the housemates of flat (or floor) depend upon each other?' (p. 129). Similarly, Muhammad et al.'s (2014) explorations of student perspective on academic buildings identified 'Participation and inclusiveness' and 'Interaction' (pp. 1167-68) among the aspects associated with wellbeing. Furthermore, many of the open plan office design features considered by Shafaghat et al. (2014) as wellbeing determinants also related to this subtheme: Facilitate communication; Accommodate knowledge sharing; Easier supervision of workers; Better feedback from colleagues; Fewer friendship opportunities. Other examples include the concept of 'Social network connectivity' at the scale of the room, lobby, courtyard or public square, explored by Abell, Alhusban, Alhusban, and Lurasi (2013, p. 359). Other papers referred to Sense of Inclusion. Alvaro et al. (2016) explored the effects of healthcare facility design on wellbeing by asking participants to indicate 'the extent to which they felt connected to each of these settings... while at the hospital: Nature, neighbourhood and city' (p. 87), while Easterbrook and Vignoles (2015) included questions such as 'How close do you feel to the other members of flat (or floor) ?' (p. 129). A few papers also included aspects related to the Familial context. Examples include 'family/social life impact' (Newsham et al., 2009, p. 146), or 'marital problems/family composition' (Bluyssen et al., 2011, p. 
2637). Two papers also referred to a different subtheme from the SOC spectrum, namely Negative Spatial Experiences. While these could arguably pertain to the ENV dimension, here they referred to issues brought on by social circumstances, such as 'safety (crime and violence), crowding (neighbourhood)' (Bluyssen et al., 2011, p. 2637) and 'Reduce(d) workstation size, Increase(d) feeling of crowding' (Shafaghat et al., 2014, p. 85).

\subsubsection{Productivity or Cognitive Performance (PRO)}

Most of the papers that conceptualised wellbeing as PRO included aspects of Cognitive Performance._Some of the authors referred to concentration (Butala \& Muhic, 2007; Turunen et al., 2013), while others used specific cognitive tests. Denk, et al. (2015) used an attention test to measure 'processing speed, rule compliance and quality of performance, as well as individual attention and concentration performance' (p. 424). Lamb et al. (2014) used the 1935 Stroop Test, while Fostervold and Nersveen (2008) used tests to measure 'Basic information processing skills', as well as 'the ability of individuals to maintain visuo-cognitive alertness for an extended period of time' (p. 182). A few papers referred to the Productivity subtheme. Some authors included measures of self-reported work performance or effectiveness in addition to the cognitive tests (Butala \& Muhic, 2007; Lamb et al. 2014). Other authors focused only on perceived productivity: Agha-Hossein et al. (2013) used the question 'My current office environment already has a positive effect on my: productivity' (p. 126-127), whereas Thatcher and Milner (2014) asked participants to rate 'how well you have been working over the last month in relation to your full capacity' on a scale of 0 to 100 (p. 386). Papers focused on educational 
environments also investigated aspects related to Learning. Muhammad et al.'s (2014) interviews with higher education students included topics such as 'Influence of academic buildings on learning and productivity', 'Students' idea about an environment conducive for learning', and 'Facilities to meet students learning needs' (p. 1165). Turunen et al. (2013) investigated the issue of difficulties in learning as well as academic performance on a maths test.

\subsubsection{Eudaimonic (EUD)}

The EUD theme was sometimes associated with notions relating to Personal growth. Alvaro et al. (2016) used the 10-item Revised Life Orientation Test and the 8-item Flourishing Scale, while Lamb et al. (2014) mentioned Motivation. Other EUD dimensions relating to $\underline{\text { Control and autonomy }}$ were discussed: Bluyssen et al. (2011) referred to 'self-efficacy and locus of control', 'job strains such as high demands and low control' (p. 2637), and Shafaghat et al. (2014) considered 'lack of autonomy' as a negative feature of open plan office design, leading to Job dissatisfaction.

\subsubsection{Other (OT) and Unspecified (UN)}

Among the wellbeing conceptual themes that could not be easily associated with any of the seven discussed above, some referred to Managerial attributes of space ('Maintenance, Operation activities, Information Management, Organisation management ', Kang et al. 2014, p.152), or aspects of Cost efficiency ('Daylight Sharing, Save office space, Lower rent cost due to higher worker density, Reduce[d] cost in maintenance', Shafaghat et al. 2014, p.85). Job or organisation-related concepts were also explored, including Presenteeism and absenteeism (Thatcher and 
Milner 2014), or Perceptions of improvement and Intention to quit (Alvaro et al. 2016).

A few papers used the term wellbeing without specifying how it had been conceptualised, for example Agha-Hossein et al. (2013) measured perceived wellbeing by asking participants to indicate their agreement with the statement 'My current office environment already has a positive effect on my: wellbeing' (p. 126127), without including any definition in the paper. Similarly, Tavakkoli et al. (2015) used a 'personal wellbeing questionnaire [that] has 8 items, each of which asks questions about one field on a 7- point likert- scale' but did not clearly state the content of the questionnaire.

\subsection{Discussion}

Overall the review of papers included in this research found that most studies adopted a heterogeneous approach to the conceptual definition(s) of wellbeing, often resulting in a 'pick and mix' of several dimensions. In some cases, papers did not explicitly define wellbeing as such, nor discussed how it was specifically evaluated in the study. Therefore, we had to read each paper with a view of interpreting these aspects, in order to assign the most relevant conceptual themes (or create a specific one, if needed). This task was especially difficult for those papers which explored several topics, other than wellbeing: in these cases, we had to select those aspects which, to the best of our ability, seemed most related to 'wellbeing' specifically. Whilst this could be considered a limitation of the study resulting in a subjective interpretation of the conceptual themes, it is also a finding worth emphasising. 
Although in some cases failure to define the term 'wellbeing' and its meaning might have arisen from an assumption that its specific interpretation was already known in the relevant academic community, on other occasions it was apparent that the term 'wellbeing' may even have been used in a vague and generic sense, possibly as a synonym of something which is generically 'good'. The idea that the pursuit of wellbeing is always desirable might appear obvious but is in fact contested. Some argue that the 'Wellness Syndrome' (Cederstrom and Spicer 2014) can lead to the exclusion or demonization of members of society who won't or cannot pursue 'wellness' or 'healthy living', and that such syndrome is being exploited by Governments and business, via the 'Happiness industry' (Davies 2015). It is argued that the emphasis on individual control/pursuit of health and happiness has the potential effect of relieving society and governments from their responsibility to support those who for whatever reason are not in a state of 'being well'.

Another notable finding is the observation that many papers failed to clarify whether wellbeing was conceptualised as an outcome (for which one has to define its meaning and/or 'dimensions'), or indirectly specified by considering those factors which determine or support wellbeing (i.e. wellbeing determinants). This is something which is perhaps inherent to the very essence of defining wellbeing, as other authors point out:

Depending on how wellbeing is conceived initially, these [aspects of human life] may be cast as either dimensions to wellbeing, or determinants of wellbeing. Thus in a hedonic psychological approach to a personal subjective wellbeing, economic and various other social elements are cast as determinants [...]. By 
contrast, a eudaimonic, economic or developmental approach attempts to define the entirety of human flourishing through independent dimensions to wellbeing, which cover a wide range of both objective and subjective components (Fuller, Atkinson, \& Painter, 2016 , p. 6)

However, as outlined in the Introduction, a research question of interest to practitioners nowadays is understanding how buildings and the wider built environment should be designed (and managed) in order to support or enhance wellbeing. This question cannot be suitably addressed by studies which do no clearly differentiate between wellbeing as an outcome, and the 'determinants' of wellbeing. In fact, such studies may end up simply perpetuating existing design paradigms. The potential confusion arising from the mismatch between outcome and determinant is apparent in studies exploring 'Environmental Quality, Satisfaction and/or Comfort' (ENV), and especially the sub-theme 'Indoor Environmental Quality'. These aspects were on occasions presented as a 'marker' of an otherwise unspecified wellbeing. The ENV theme was not initially included in the "conceptual approaches' to wellbeing as arising from the review of mainstream definitions (section 2). It is perhaps unsurprising that this specific theme was found within a research field which is concerned with the relationship between buildings and wellbeing. What is surprising though is the lack of discussion which we encountered in several relevant papers as to whether 'satisfaction' with the environment is per se an outcome, or one of the determinants of wellbeing. Moreover, the relative 'weight' of 'environmental satisfaction' in relation to other wellbeing dimensions (outcomes) or determinants was rarely debated. 
Similarly, a conceptual theme that was deducted from the papers was 'Productivity or Cognitive Performance' (PRO). The relevance of this theme to wellbeing is perhaps aligned with Eudaimonic approaches - although PRO would represent only one of the many dimensions contributing to Eudaimonic wellbeing. Again, some papers did not discuss to what extent one should seek to provide environmental conditions which are believed to optimise 'productivity', without addressing other dimensions of wellbeing.

Regarding other themes and sub-themes relevant to buildings, it can be observed how certain aspects clearly cut across different themes: for example, stress and positive/negative affect could be conceptualised as belonging to both 'Hedonic' or 'Mental Health'. 'Satisfaction' with the physical or social work environment could pertain the 'Hedonic/Subjective' theme, but also pertain respectively the ENV or SOC (social) theme. Several other examples can be provided of the cross-cutting nature of themes and sub-themes. Whilst this is inherent perhaps to the 'slippery' nature of wellbeing, it reinforces the importance of explicitly discussing the causal pathways and mechanisms which are being investigated within studies, as opposed to assuming these are known and widely understood.

\subsection{Limitations}

Finally, the limitations of this study should be acknowledged. The most obvious limitation has already been referred to earlier: the inevitable subjective nature of the conceptual themes derived in this study, and of how we had to interpret or assign these themes to each paper. Such subjectivity was compounded by the lack of 
clarity which we encountered in several papers regarding conceptualisations and definitions of wellbeing. Moreover, it is worth mentioning that the themes used as a starting point in this review were derived from literature focusing on developed countries. While this may reflect that more research on this topic is performed in certain countries, it may also act as an unintended bias of our review.

The second potential limitation of this study is how its inclusion/exclusion criteria would have affected the pool of papers eventually included. For example, the inevitable exclusion of the vast body of literature comprising restorative environments, healthcare facilities, or papers focusing mainly on diagnosable diseases has resulted in a limited number of studies addressing the Physical or Mental Health themes, and as such the nuances within the relevant sub-themes discussed here are possibly limited. The lack of papers discussing the economic conceptualisation of wellbeing is also notable and we believe this finding cannot be entirely attributed to an artefact of our exclusion criteria.

\subsection{Implications and further work}

As shown above, the relationship between wellbeing and buildings is heterogenous and often involves more than one dimension. Therefore, the themes identified in this study should be interpreted as an opportunity to initiate discussion within the global academic community of their relevance, applicability, and of whether some dimensions of wellbeing are glaringly missing.

Several recommendations can be made for future evidence-based research addressing wellbeing in buildings: 
- Define 'wellbeing' in a clear and unambiguous way. Conceptual approaches may include one or several dimensions - in the latter case, provide definitions of all constructs taken into account.

- Explain the causal pathway hypothesised by the research: clearly state whether 'wellbeing' is an outcome, a mediator or a determinant of other research outcome(s). This is particularly important in cases when 'environmental satisfaction', 'stress' or 'affect' constructs are used.

Another potential recommendation would be to consider using established methods and tools (e.g. questionnaires) to 'measure' specific aspects of wellbeing which might have already been applied in built environment research or other relevant disciplines. This would add clarity and comparability. However, established measurement tools borrowed from other fields may not always be suitable or even useful for built environment applications.

Our study also reveals an opportunity for future work required to develop guidance in how to evaluate claims of evidence-based building design(s) which foster individual or population wellbeing. Indeed, this area — development and validation of useful wellbeing-related metrics which can demonstrate the 'value' of design - is likely to be a fecund research area. More recent publications include a blend of a psychological wellbeing model, quantitative measurement and financial reporting (Watson, 2018). While the recommendations presented above may serve as a starting point, more research is needed to identify and address other important aspects. 


\subsection{Conclusions}

This paper aimed to review the prevailing conceptual approaches to the definition(s) of 'wellbeing' presented in the academic literature within the context of buildings. Starting with a review of the origins and main theoretical approaches to wellbeing, this study identified preliminary wellbeing themes which were subsequently refined or augmented through a deductive review of papers included in this study. The final nine conceptual themes were: Hedonic, Eudaimonic or Social Wellbeing, Physical or Mental Health, Environmental Satisfaction, Productivity (or Cognitive Performance), plus Other and Unspecified theme. Environmental Satisfaction and Productivity emerged deductively from the papers and did not feature in the initial review of mainstream definitions of wellbeing. Conversely, no papers addressed wellbeing notions especially aligned with the economic literature.

The review revealed great heterogeneity across approaches, with several aspects of wellbeing being investigated within the same paper. On occasions, there was also a failure to clarify whether such aspects were conceptualized as a specific wellbeing outcome, or if wellbeing was investigated indirectly, via analysis of determinants. Several papers did not discuss how different wellbeing dimensions related to each other, in determining overall individual or population wellbeing. This lack of clarity is problematic, when considering the current need for evidence-based approaches to identifying how building design/management can foster 'wellbeing'. Of particular interest to the built environment community is the need to understand 
further to what extent environmental satisfaction or comfort is a determinant or a dimension of wellbeing, and how it relates to other wellbeing aspects.

As the Introduction highlights, in the current industry-led discourse the term wellbeing (in buildings) is often accompanied by 'health' and on occasion substituted by 'wellness'. Despite the WHO definition of 'health', this term is a field primarily led by public health, epidemiology and healthcare professionals whose main focus is the understanding, avoidance and management of disease and ill-health. However, since it is acknowledged that the absence of disease and ill-being does not automatically result in being well, several sciences - including those relevant to the built environment - can now contribute to the definition of wellbeing, and its active pursuit (i.e. wellness?). Not all, however, agree that such pursuit is always good for society or individuals, arguing that the 'wellbeing syndrome' should not be acratically welcomed.

Whilst the focus of public health and policy on poor environmental conditions is not new, a novel and almost parallel movement amongst built environment professionals can now be observed: the pursuit of wellbeing. This is a subtle but significant shift away from 'avoidance of risk and disease 'towards an active pursuit of 'adding value', through the fostering of wellbeing. Indeed, many professionals are being attracted to the health and wellbeing agenda by this powerful idea. Therein lies a challenge, and an opportunity.

In light of the industry-led renewed interest in wellbeing in buildings, and of the heterogeneous approach to conceptual definitions of wellbeing observed in the papers included in this study, it is imperative that the academic community adopts a 
leadership role to avoid that current industry efforts result in a reductionist and conveniently selective definition of 'wellbeing', and of the evidence underpinning the 'wellbeing in buildings revolution'.

\section{References}

Note: Articles included in the Wellbeing and Buildings review are marked with an asterisk $(*)$.

*Abell, J., Alhusban, A., Alhusban, S., \& Lurasi, S. (2013). Habitat, housing social connectivity to promote social well-being. International Journal of Design \& Nature and Ecodynamics, 8(4), 356-371.

*Agha-Hossein, M. M., El-Jouzi, S., Elmualim, A. A., Ellis, J. \& Williams, M. (2013). Post-occupancy studies of an office environment: Energy performance and occupants' satisfaction. Building and Environment, 69, 121-130.

*Alvaro, C., Wilkinson, A. J., Gallant, S. N., Kostovski, D. \& Gardner, P. (2016). Evaluating intention and effect: The impact of healthcare facility design on patient and staff well-Being. Health Environments Research \& Design Journal, 9(2), 82-104.

Bell, S. L., Foley, R., Houghton, F., Maddrell, A., \& Williams, A. M. (2018). From therapeutic landscapes to healthy spaces, places and practices: A scoping review. Social Science \& Medicine, 196, 123-30. 
Berger, P. L. \& Luckman, T. (1966). The social construction of reality: A treatise in the sociology of knowledge. Garden City, NY: Doubleday.

Bernstein, D.A., Penner, L.A., Clarke-Stewart, A., \& Roy, E.J. (2003). Psychology (6th ed.). Boston: Houghton Mifflin Co.

*Bluyssen, P. M., Janssen, S., Van den Brink, L. H., De Kluizenaar, Y. (2011). Assessment of wellbeing in an indoor office environment. Building and Environment, 46(12), 2632-2640.

*Butala, V., \& Muhič, S. (2007). Perception of air quality and the thermal environment in offices. Indoor and Built Environment, 16(4), 302-310.

Cascio, W.F. (1987). Applied Psychology in Personnel Management (3rd ed.). Englewood Cliffs, NJ: Prentice-Hall.

Cederstrom, C. \& Spicer, A. (2014). The wellness syndrome. Cambridge UK: Polity Press.

Centers for Disease Control. (2018). Fitwel is the world's leading certification system that optimizes buildings to support health [webpage]. Retrieved from: https://fitwel.org/.

Christopher, J. (1999). Situating psychological well-being; Exploring the cultural roots of its theory and research. Journal of Counselling and Development, 77, $141-152$. 
Cieslik, M. (2015). 'Not smiling but frowning': Sociology and the 'problem of happiness'. Sociology, 49(3), 422-437.

Costanza, R., Fisher, B., Ali, S., Beer, C., Bond, L., Boumans, R., ... Snapp, R. (2007). Quality of life: An approach integrating opportunities, human needs, and subjective well-being. Ecological Economics, 61(2), 267-276.

Cronin de Chavez, A., Backett-Milburn, K., Parry, O., \& Platt, S. (2005).

Understanding and researching wellbeing: Its usage in different disciplines and potential for health research and health promotion. Health Education Journal, 64(1), 70-87.

Davies, W. (2015). The happiness industry: How the government and big business sold us well-being. London: Verso Books.

*Denk, E., Jimenez, P., \& Schulz, B. (2015). The impact of light source technology and colour temperature on the well-being, mental state and concentration of shop assistants. Lighting Research and Technology, 47(4), 419-433.

Diener, E. (2009). Subjective well-being. In E. Diener (Ed.), The science of wellbeing (pp. 11-58). New York: Springer.

Diener, E. \& Seligman, M. E. P. (2004). Beyond money: Toward an economy of well-being. Psychological Science in the Public Interest, 5(1), 1-31. 
Diener, E. \& Suh, E. (1997). Measuring quality of life: Economic, social and subjective indicators. Social Indicators Research, 40(1-2), 189-216.

Diener, E., Emmons, R. A., Larsen, R.J., \& Griffin, S. (1985). The satisfaction with life scale. Journal of Personality Assessment, 49(1), 71-75.

Dodge, R., Daly, A. P., Huyton, J, \& Sanders, L. D. (2012). The challenge of defining wellbeing. International Journal of Wellbeing, 2(3), 222-235.

*Easterbrook, M. J., \& Vignoles, V. L. (2015). When friendship formation goes down the toilet: Design features of shared accommodation influence interpersonal bonds and well-being. British Journal of Social Psychology, 54(1), 125-139.

Elsevier (2018). SCOPUS: An eye on global research. [webpage]. Retrieved from: https://www.elsevier.com/solutions/scopus.

Forgeard, M. J. C., Jayawickreme, E., Kern, M. L., \& Seligman, M. E. P. (2011). Doing the right thing: Measuring wellbeing for public policy. International Journal of Wellbeing, 1(1), 79-106.

*Fostervold, K., \& Nersveen, J. (2008). Proportions of direct and indirect indoor lighting -- The effect on health, well-being and cognitive performance of office workers. Lighting Research and Technology, 40, 175-200.

Fuller, S., Atkinson, S., \& Painter, J. (Eds.). (2016). Wellbeing and Place. Routledge: London. 
Gable, S. L, \& Haidt, J. (2005). What (and why) is positive psychology? Review of General Psychology, 9, 103-110.

Gasper, D. (2005). Subjective and objective well-being in relation to economic inputs: puzzles and responses. Review of Social Economy, 63(2), 177-206.

Grant, M.J. Booth, A. (2009). A typology of reviews: An analysis of 14 review types and associated methodologies. Health Information and Libraries Journal, 26(2), 91-108.

Headey, B., \& Wooden, M. (2004). The effects of wealth and income on subjective well-being and ill-being. Discussion paper No. 1032, February 2004. Bonn: Forschungsinstitut zur Zukunft der Arbeit (IZA).

Headey, B., \& Wearing, A.J. (1989). Personality, life events and subjective wellbeing: Toward a dynamic equilibrium model. Journal of Personality and Social Psychology, 57(4), 731-739.

Helliwell, J. F., \& Putnam, R. D. (2004). The social context of well-being. Philosophical Transactions of The Royal Society B, 359(1449), 1435-1446.

Huppert, F. A. (2017). Challenges in defining and measuring well-being and their implications for policy. In: M. A. White, G. Slemp, \& A. S. Murray (Eds.) 
Future Directions in Well-Being: Education, Organizations and Policy (pp.163-167). Cham: Springer.

Huppert, F. A., \& So, T. T. C. (2013). Flourishing across Europe: Application of a new conceptual framework for defining wellbeing. Social Indicators Research, 110(3), 837-861.

Ibem, E. O., Opoko, A. P., Adeboye, A. B. \& Amole, D. (2013). Performance evaluation of residential buildings in public housing estates in Ogun State, Nigeria: Users' satisfaction perspective. Frontiers of Architectural Research, 2(2), 178-190.

Kahneman, D. (2003). Puzzles of well-being. Paper presented at the Annual Meeting of the American Economics Association, Washington, DC.

Kahneman, D., Diener, E. and Schwartz, N. (1999). Well-being: The Foundations of Hedonic Psychology. New York: Sage.

*Kang, N. N., Lee, T. K., Kim, J. T., Kim, C. G. (2014). Residents' and experts’ perspectives for evaluation of importance of Health Performance Indicators in social housings. Indoor and Built Environment, 23(1), 150-160.

Keyes, C. L. M. (1998). Social well-being. Social Psychology Quarterly, 61(2), 121140. 
Keyes, C. L. M., Shmotkin, D., \& Ryff, C.D. (2002). Optimizing well-being: The empirical encounter of two traditions. Journal of Personality and Social Psychology. 82(6), 1007-1022.

*Lamb, S., Kwok, K. C. S., \& Walton, D. K. (2014). A longitudinal field study of the effects of wind-induced building motion on occupant wellbeing and work performance. Journal of Wind Engineering and Industrial Aerodynamics, 133, $39-51$.

Larson, J. S. (1992). The measurement of social well-being. Social Indicators Research, 28, 285-296.

Layard, R. (2005). Happiness: Lessons from a New Science. Penguin: London.

Layard, R., Clark, A. E., Cornaglia, F., Powdthavee, N., \& Vernoit, J. (2013). What predicts a successful life? A life-course model of well-being. Centre for Economic Performance Discussion Paper No.1245, October 2013, The LSE.

*Lee, J., Je, H., \& Byun, J. (2011). Well-Being index of super tall residential buildings in Korea. Building and Environment, 46(5), 1184-1194.

Levac, D., Colquhoun, H., \& O’Brien, K. K. (2010). Scoping studies: advancing the methodology. Implementation Science, 5(1), 5-69.

Mahoney, T.A. (1988). Productivity defined: The relativity of efficiency, effectiveness, and change. In: J.P. Campbell, R.J. Campbell and Associates 
(Eds.). Productivity in Organizations: New Perspectives from Industrial and Organizational Psychology (pp.13-39). San Francisco: Jossey-Bass.

McDowell, I., \& Newell, C. (1987). Measuring health: A guide to rating scales and questionnaires. New York: Oxford University Press.

Michaelson, J., Abdallah, S., Steuer, N., Thompson, S., \& Marks, N. (2009). National accounts of well-being: Bringing real wealth onto the balance sheet. London: New Economics Foundation.

*Muhammad, S., Sapri, M., \& Sipan, I. (2014). Academic Buildings and Their Influence on Students' Wellbeing in Higher Education Institutions. Social Indicators Research, 115, 1159-1178.

*Neuner, R., \& Seidel, H.-J. (2006). Adaptation of office workers to a new building Impaired well-being as part of the sick-building-syndrome. International Journal of Hygiene and Environmental Health, 209(4), 367-375.

New Economics Foundation (2012). Measuring well-being: A guide for practitioners. London: New Economics Foundation.

*Newsham, G., Brand, J., Donnelly, C., Veitch, J., Aries, M., \& Charles, K. (2009). Linking indoor environment conditions to job satisfaction: A field study. Building Research and Information. 37(2), 129-147. 
Oxford English Dictionary (2016a) “wellbeing, n.” OED Online. Oxford University

Press. [webpage, September 2016]. Retrieved from:

http://www.oed.com/view/Entry/227050?redirectedFrom=wellbeing\#eid.

Oxford English Dictionary (2016b). "wellness, n.” OED Online. Oxford University

Press. [webpage, September 2016]. Retrieved from:

http://www.oed.com/view/Entry/227459?redirectedFrom=wellness\#eid.

*Pelenur, M. J., \& Cruickshank, H.J. (2013). Investigating the link between wellbeing and energy use; an explorative case study between passive and active domestic energy management systems. Building and Environment. 65, 26-34.

Pham, M. T., Rajić, A., Greig, J. D., Sargeant, J. M., Papadopoulos, A., \& McEwen, S.A. (2014). A scoping review of scoping reviews: Advancing the approach and enhancing the consistency. Research Synthesis Methods. 5(4), 371-385.

Pollard, E. \& Lee, P. (2003). Child well-being: A systematic review of the literature. Social Indicators Research, 61(1), 9-78.

Reber, A. (1995). Dictionary of Psychology - Second Edition. Harmonsworth: Penguin.

*Rioux, L. (2005). The well-being of aging people living in their own homes. Journal of Environmental Psychology, 25, 231-243. 
Ryan, R. M., \& Deci, E. L. (2001). To be happy or to be self-fulfilled: A review of research on hedonic and eudaimonic well-being. In: S. Fiske (Ed.), Annual Review of Psychology, 52, 141-166. Palo Alto, CA: Annual Reviews Inc.

Ryan, R. M., \& Huta, V. (2009). Wellness as healthy functioning or wellness as happiness: The importance of eudaimonic thinking (response to the Kashdan et al. and Waterman discussion). The Journal of Positive Psychology, 4(3), $202-204$.

Ryff, C.D., \& Singer, B. (1998). The contours of positive human health. Psychological Inquiry. 9(1), 1-28.

Seligman, M. E. P. (2011). Flourish: A Visionary New Understanding of Happiness and Well-Being. New York: Free Press.

Seligman, M. E. P., Parks, A.C., \& Steen, T. (2004). A balanced psychology and a full life. Philosophical Transactions of the Royal Society B: Biological Sciences. 359(1449), 1379-1381.

Sen, A. (1999). Development as Freedom. Oxford: Oxford University Press.

*Shafaghat, A., Keyvanfar, A., Lamit, H., Mousavi, S.A., Zaimi, M., \& Majid, A. (2014). Open Plan Office Design Features Affecting Staff's Health and Wellbeing Status. Jurnal Teknologi, 70, 83-88. 
Shin, D. C. \& Johnson, D.M. (1978). Avowed happiness as an overall assessment of the quality of life. Social Indicators Research, 5, 475-492.

Shin, J. (2015). Toward a theory of environmental satisfaction and human comfort: A process-oriented and contextually sensitive theoretical framework. Journal of Environmental Psychology,45, 11-21.

Siegler, V. (2015, January 29). Measuring national wellbeing - An analysis of social capital in the UK. [web archive]. Retrieved from: http://webarchive.nationalarchives.gov.uk/20160105160709/http://www.ons.g ov.uk/ons/dcp171766_393380.pdf.

*Steemers, K., \& Manchanda, S. (2010). Energy efficient design and occupant wellbeing: Case studies in the UK and India. Building and Environment, 45(2), $270-278$.

Stigliz, J., Sen, A. \& Fitoussi, J.P. (2009). Report by the commission on the measurement of economic performance and social progress. [web document]. Retrieved from: http://ec.europa.eu/eurostat/documents/118025/118123/Fitoussi+Commission +report.

Tatarkiewicz, W. (1976). Analysis of Happiness. The Hague, Netherlands: Martinus Nijhoff. 
*Tavakkoli, S., Asaadi, M.,M., Pakpour, A.H., \& Hajiaghababaei, M. (2015).

Environmental Psychology Effects on Mental Health Job. Iranian Journal of Psychiatry. 10(3), 158-164.

*Thatcher, A., \& Milner, K. (2014). Changes in productivity, psychological wellbeing and physical wellbeing from working in a 'green' building. Work, 49(3), 381-393.

*Torrington, J. (2007). Evaluating quality of life in residential care buildings. Building Research \& Information, 35(5), 514-528.

*Turunen, M., Toyinbo, O. ,Putus, T., Nevalainen, A., Shaughnessy, R., \& Haverinen-Shaughnessy, U. (2013). Indoor environmental quality in school buildings, and the health and wellbeing of students. International Journal of Hygiene and Environmental Health, 217(7), 733-739.

UK Green Building Council (UKGBC, 2016). Health and wellbeing in homes. [webpage]. Retrieved from: https://www.ukgbc.org/sites/default/files/08453\%20UKGBC\%20Healthy\%20 Homes $\% 20$ Updated $\% 2015 \% 20$ Aug $\% 20$ (spreads).pdf.

UKGBC. (2017a). Health and Wellbeing. [webpage]. Retrieved from: https://www.ukgbc.org/health-and-wellbeing/. 
UKGBC. (2017b). UKGBC wellbeing lab offices: A compendium of experience. [webpage]. Retrieved from: https://www.ukgbc.org/ukgbc-work/uk-gbcwellbeing-lab-offices-compendium-experience/.

United Nations Development Programme. (UNDP, 2018). Human Development Index (HDI) | Human Development Reports. [webpage]. Retrieved from: http://hdr.undp.org/en/content/human-development-index-hdi.

Veenhoven, R. (2008). Sociological theories of subjective wellbeing. In: M. Eid \& R. Larsen (Eds). The Science of Subjective Well-being: A tribute to Ed Diener. New York: Guilford Publications.

Watson, K. (2018). Establishing psychological wellbeing metrics for the built environment. Building Services Engineering Research and Technology, 39(2), 232- 243.

World Green Building Council (WGBC, 2014). Health, wellbeing \& productivity in offices: The next chapter for green buildings. [webpage]. Retrieved from: http://www.worldgbc.org/news-media/health-wellbeing-and-productivityoffices-next-chapter-green-building.

WGBC, (2016a). Better places for people. [webpage]. Retrieved from: http://www.worldgbc.org/better-places-people.

WGBC, (2016b). Health, wellbeing and productivity in retail: The impact of green buildings on people and profit. [webpage]. Retrieved from: 
http://www.worldgbc.org/news-media/health-wellbeing-and-productivityretail-impact-green-buildings-people-and-profit.

*Wilson, J., Dixon, S. L., Jacobs, D.E., Breysse, J., Akoto, J., Tohn, E...., Hernandez, Y. (2014). Watts-to-Wellbeing: Does residential energy conservation improve health? Energy Efficiency, 7(1), 151-160.

World Bank (1998). The Initiative of Defining, Monitoring and Measuring Social Capital. Social Capital Initiative: Text of Proposals Approved for Funding.. [Working Paper No. 29280, 01 June 1998]. Retrieved from: http://documents.worldbank.org/curated/en/111741468767413539/Theinitiative-on-defining-monitoring-and-measuring-social-capital-text-ofproposals-approved-for-funding.

World Health Organization (2006). Constitution of the World Health Organization. [Basic Documents, Forty-Fifth Ed., Supplement, October 2016] Retrieved from: http://www.who.int/governance/eb/who_constitution_en.pdf.

*Wu, S., \& Noy, P. 2010. A conceptual design of a wireless sensor actuator system for optimizing energy and well-being in buildings. Intelligent Buildings International. 2(1), 41-56. 


\section{Appendix}

\section{Table A-1. Description of wellbeing conceptual themes used in the review}

\begin{tabular}{|c|c|}
\hline Wellbeing theme & Description \\
\hline $\begin{array}{l}\text { Environmental Satisfaction, } \\
\text { Quality and / or Comfort } \\
\text { (ENV) }\end{array}$ & $\begin{array}{l}\text { Environmental satisfaction is defined by lbem et al. (2013) as the subjective appraisal } \\
\text { of the objective qualities of an environment. This is grounded in judgement about how } \\
\text { much the environment meets the users' needs and expectations. We adopt Shin's } \\
\text { (2015) definition of environmental comfort as the 'physical/physiological sensation and } \\
\text { perception of discrete environmental stimuli from one's immediate surroundings' (p. } \\
\text { 4). }\end{array}$ \\
\hline $\begin{array}{l}\text { Hedonic or Subjective } \\
\text { Wellbeing } \\
\text { (HED) }\end{array}$ & $\begin{array}{l}\text { Historically associated with 'happiness', Ryan and Deci (2001) note subjective } \\
\text { wellbeing 'consists of three components: life satisfaction, the presence of positive } \\
\text { mood, and the absence of negative mood, together often summarized as happiness' } \\
\text { (p. 144). It is characterised in contemporary literature as the balance of positive / } \\
\text { negative affect, the evaluation of satisfaction with various domains of life (e.g. work, } \\
\text { leisure), and/or global life satisfaction (Keyes, Shmotkin, \& Ryff, 2002). Life } \\
\text { satisfaction has been described as the 'hallmark' of subjective wellbeing (Diener et al., } \\
\text { 1985), defined by Shin and Johnson (1978) as 'a global assessment of a person's } \\
\text { quality of life according to his chosen criteria' (p. 478). Tatarkiewicz (1976) has noted } \\
\text { that 'happiness requires total satisfaction, that is satisfaction with life as a whole' (p. } \\
\text { 8). Quality of life is a similarly broad term used to represent "how well human needs } \\
\text { are met or the extent to which individuals or groups perceive satisfaction or } \\
\text { dissatisfaction in various life domains" (Costanza et al., 2007, p. 267). }\end{array}$ \\
\hline $\begin{array}{l}\text { Physical Health } \\
\text { (PH) }\end{array}$ & $\begin{array}{l}\text { This category refers to physical health, which we view through the definitional lens of } \\
\text { Veenhoven (2008) as the "absence of illness or defect" ( } p \text {. 450). As Veenhoven notes, } \\
\text { physical health is an objective measure attained through medical assessments or } \\
\text { subjective self-reports. }\end{array}$ \\
\hline $\begin{array}{l}\text { Mental Health } \\
(\mathrm{MH})\end{array}$ & $\begin{array}{l}\text { III-being (which has also been characterised as psychological distress) has been } \\
\text { noted to include anxiety, depression and other negative effects (Headey and Wooden, } \\
\text { 2004). This paper excludes conditions with a more enduring pathology such as } \\
\text { schizophrenia and bi-polar disorders. }\end{array}$ \\
\hline $\begin{array}{l}\text { Social Wellbeing } \\
\text { (SOC) }\end{array}$ & $\begin{array}{l}\text { Social well-being has been characterised along the dimensions of social integration, } \\
\text { social contribution, social cohesion, social actualisation and social acceptance } \\
\text { (Keyes, 1998). Recent definitions have included the notion of 'social capital' (see for } \\
\text { instance, Helliwell \& Putnam, 2004). }\end{array}$ \\
\hline $\begin{array}{l}\text { Productivity and Cognitive } \\
\text { Performance } \\
\text { (PRO) }\end{array}$ & $\begin{array}{l}\text { Although there is no single accepted definition of productivity, there is consensus that } \\
\text { productivity must be defined in terms of a ratio of output variables to input variables } \\
\text { (Cascio, 1987; Mahoney, 1988). Conversely, cognitive performance is defined as the } \\
\text { capacity to perform mental processes, this extends across a variety of basic cognitive } \\
\text { functions such as reasoning, understanding, remembering and problem solving } \\
\text { (Bernstein, Penner, Clarke-Stewart, \& Roy, 2003). }\end{array}$ \\
\hline $\begin{array}{l}\text { Eudaimonic Wellbeing } \\
\text { (EUD) }\end{array}$ & $\begin{array}{l}\text { Traditionally connected with the term 'human potential' (see Ryan \& Deci, 2001), } \\
\text { today psychological well-being is described as the 'perception of engagement with } \\
\text { existential challenges of life' (Keyes, Shmotkin, \& Ryff, 2002, p. 1007). This has been } \\
\text { characterised as a sense of control or autonomy, feeling of meaning and purpose, } \\
\text { personal expressiveness, feelings of belongingness, social contribution, competence, } \\
\text { personal growth, and self-acceptance. }\end{array}$ \\
\hline Other & $\begin{array}{l}\text { This categorisation is used to capture conceptualisations and/or proxies of wellbeing } \\
\text { that are not included in the above. }\end{array}$ \\
\hline Unspecified & $\begin{array}{l}\text { The authors of the paper do not provide a definition or detail on how they } \\
\text { operationalised wellbeing. }\end{array}$ \\
\hline
\end{tabular}


Table A -2. Wellbeing and buildings: Conceptual themes and subthemes used by the papers included in review.

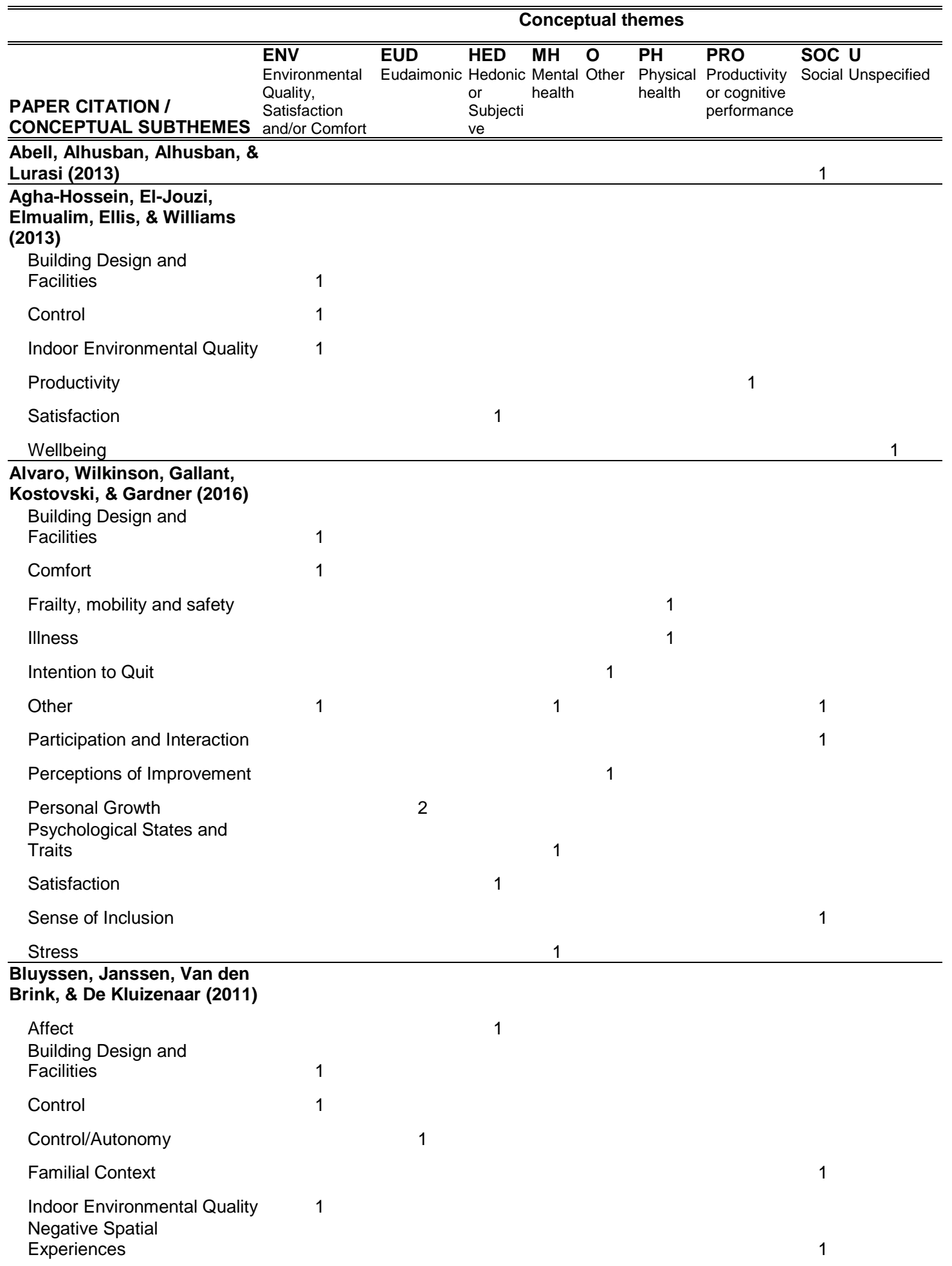


Table A -2. Wellbeing and buildings: Conceptual themes and subthemes used by the papers included in review.

\begin{tabular}{|c|c|c|c|c|c|c|c|c|}
\hline \multirow[b]{2}{*}{$\begin{array}{l}\text { PAPER CITATION / } \\
\text { CONCEPTUAL SUBTHEMES } \\
\end{array}$} & \multicolumn{8}{|c|}{ Conceptual themes } \\
\hline & $\begin{array}{l}\text { ENV } \\
\text { Environmental } \\
\text { Quality, } \\
\text { Satisfaction } \\
\text { and/or Comfort }\end{array}$ & $\begin{array}{l}\text { EUD } \\
\text { Eudaimonic }\end{array}$ & $\begin{array}{l}\text { HED } \\
\text { Hedonic } \\
\text { or } \\
\text { Subjecti } \\
\text { ve } \\
\end{array}$ & $\begin{array}{l}\text { MH } \\
\text { Mental } \\
\text { health } \\
\end{array}$ & $\begin{array}{l}\mathbf{O} \\
\text { Other }\end{array}$ & $\begin{array}{l}\text { PH } \\
\text { Physical } \\
\text { health }\end{array}$ & $\begin{array}{l}\text { PRO } \\
\text { Productivity } \\
\text { or cognitive } \\
\text { performance }\end{array}$ & $\begin{array}{l}\text { SOC U U } \\
\text { Social Unspecified }\end{array}$ \\
\hline Other & & & & & & & & 1 \\
\hline $\begin{array}{l}\text { Participation and Interaction } \\
\text { Psychological States and } \\
\text { Traits }\end{array}$ & & & & 1 & 1 & & & 1 \\
\hline Self-reported symptoms & & & & & & 1 & & \\
\hline Sick Building Syndrome & & & & & & 1 & & \\
\hline
\end{tabular}

Butala \& Muhič (2007)

Affect

1

Building Design and

Facilities

1

Cognitive Performance

Indoor Environmental Quality

1

Productivity

1

Self-reported symptoms

2

Stress

Denk, Jimenez, \& Schulz

(2015)

Affect

Cognitive Performance

Comfort

1

Psychological States and

Traits

Easterbrook \& Vignoles

(2015)

Affect

1

$\begin{array}{ll}\text { Participation and Interaction } & 1\end{array}$

Sense of Inclusion

1

\section{Fostervold \& Nersveen}

(2008)

Affect

Building Design and

Facilities

Cognitive Performance

Indoor Environmental Quality

Psychological States and

Traits

Satisfaction

Self-reported symptoms

1

Stress

1 
Table A -2. Wellbeing and buildings: Conceptual themes and subthemes used by the papers included in review.

\begin{tabular}{|c|c|c|c|c|c|c|c|c|}
\hline \multirow[b]{2}{*}{$\begin{array}{l}\text { PAPER CITATION / } \\
\text { CONCEPTUAL SUBTHEMES }\end{array}$} & \multicolumn{8}{|c|}{ Conceptual themes } \\
\hline & $\begin{array}{l}\text { ENV } \\
\text { Environmental } \\
\text { Quality, } \\
\text { Satisfaction } \\
\text { and/or Comfort }\end{array}$ & $\begin{array}{l}\text { EUD } \\
\text { Eudaimonic }\end{array}$ & $\begin{array}{l}\text { HED } \\
\text { c Hedonic } \\
\text { or } \\
\text { Subjecti } \\
\text { ve }\end{array}$ & $\begin{array}{l}\text { MH } \\
\text { Mental } \\
\text { health }\end{array}$ & $\begin{array}{l}\text { O } \\
\text { I Other }\end{array}$ & $\begin{array}{l}\text { PH } \\
\text { Physical } \\
\text { health }\end{array}$ & $\begin{array}{l}\text { PRO } \\
\text { Productivity } \\
\text { or cognitive } \\
\text { performance }\end{array}$ & $\begin{array}{l}\text { SOC U } \\
\text { Social Unspecified }\end{array}$ \\
\hline $\begin{array}{l}\text { Kang, Lee, Kim, \& Kim (2014) } \\
\text { Building Design and } \\
\text { Facilities }\end{array}$ & 1 & & & & & & & \\
\hline Indoor Environmental Quality & 1 & & & & & & & \\
\hline Managerial & & & & & 1 & & & \\
\hline Other & & & & & & & & 1 \\
\hline Participation and Interaction & & & & & & & & 1 \\
\hline Sense of Inclusion & & & & & & & & 1 \\
\hline
\end{tabular}

Lamb, Kwok, \& Walton (2014)

Affect

Cognitive Performance

Illness

Indoor Environmental Quality

Other

Personal Growth

Productivity

Satisfaction

Self-reported symptoms

Stress

Lee, Je, \& Byun (2011)

Building Design and

Facilities

1

Frailty, mobility and safety Muhammad, Sapri, \& Sipan

(2014)

Building Design and

Facilities

1

Indoor Environmental Quality 1

Learning

Participation and Interaction

1

1

1

\section{1}

1

2

1

Productivity

Neuner and Seidel (2006)

Control

1

Happiness

1

Indoor Environmental Quality

1

Self-reported symptoms 
Table A -2. Wellbeing and buildings: Conceptual themes and subthemes used by the papers included in review.

\begin{tabular}{|c|c|c|c|c|c|c|c|c|}
\hline \multirow[b]{2}{*}{$\begin{array}{l}\text { PAPER CITATION / } \\
\text { CONCEPTUAL SUBTHEMES }\end{array}$} & \multicolumn{8}{|c|}{ Conceptual themes } \\
\hline & $\begin{array}{l}\text { ENV } \\
\text { Environmental } \\
\text { Quality, } \\
\text { Satisfaction } \\
\text { and/or Comfort }\end{array}$ & $\begin{array}{l}\text { EUD } \\
\text { Eudaimonic }\end{array}$ & $\begin{array}{l}\text { HED } \\
\text { Hedonic } \\
\text { or } \\
\text { Subjecti } \\
\text { ve }\end{array}$ & $\begin{array}{l}\text { MH } \\
\text { Mental } \\
\text { health }\end{array}$ & $\begin{array}{l}\mathbf{O} \\
\text { Other }\end{array}$ & $\begin{array}{l}\text { PH } \\
\text { Physical } \\
\text { health }\end{array}$ & $\begin{array}{l}\text { PRO } \\
\text { Productivity } \\
\text { or cognitive } \\
\text { performance }\end{array}$ & $\begin{array}{l}\text { SOC U U } \\
\text { Social Unspecified }\end{array}$ \\
\hline \multicolumn{9}{|l|}{ Newsham et al. (2009) } \\
\hline $\begin{array}{l}\text { Affect } \\
\text { Building Design and } \\
\text { Facilities }\end{array}$ & 1 & & 1 & & & & & \\
\hline Familial Context & & & & & & & & 1 \\
\hline Indoor Environmental Quality & 1 & & & & & & & \\
\hline Satisfaction & & & 1 & & & & & \\
\hline Self-reported symptoms & & & & & & 2 & & \\
\hline Stress & & & & 1 & & & & \\
\hline \multicolumn{9}{|l|}{$\begin{array}{l}\text { Pelenur \& Cruickshank } \\
\text { (2013) }\end{array}$} \\
\hline Affect & & & 1 & & & & & \\
\hline Other & 1 & & & & & & & \\
\hline
\end{tabular}

\section{Rioux (2005)}

Other

Participation and Interaction

Satisfaction

Shafaghat et al (2014)

Building Design and

Facilities

Control/Autonomy

Cost Efficiency

Illness

Indoor Environmental Quality

Negative Spatial

Experiences

Participation and Interaction

Sick Building Syndrome

Stress

Steemers \& Manchanda

(2010)

Indoor Environmental Quality

Satisfaction

1

1

1

1

\section{1}

2

1

\begin{tabular}{ll}
\hline 1 & 1 \\
1 & 1 \\
1 & 1
\end{tabular}

Self-reported symptoms

Tavakkoli, Asaadi, Pakpour,

\& Hajiaghababaei (2015)

Illness

1
1 
Table A -2. Wellbeing and buildings: Conceptual themes and subthemes used by the papers included in review.

\begin{tabular}{|c|c|c|c|c|c|c|c|c|c|}
\hline \multirow[b]{2}{*}{$\begin{array}{l}\text { PAPER CITATION / } \\
\text { CONCEPTUAL SUBTHEMES } \\
\end{array}$} & \multicolumn{9}{|c|}{ Conceptual themes } \\
\hline & $\begin{array}{l}\text { ENV } \\
\text { Environmental } \\
\text { Quality, } \\
\text { Satisfaction } \\
\text { and/or Comfort } \\
\end{array}$ & $\begin{array}{l}\text { EUD } \\
\text { Eudaimonic }\end{array}$ & $\begin{array}{l}\text { HED } \\
\text { Hedonic } \\
\text { or } \\
\text { Subjecti } \\
\text { ve }\end{array}$ & $\begin{array}{l}\text { MH } \\
\text { Mental } \\
\text { health }\end{array}$ & $\begin{array}{l}\mathbf{O} \\
\text { Other }\end{array}$ & $\begin{array}{l}\text { PH } \\
\text { Physical } \\
\text { health }\end{array}$ & $\begin{array}{l}\text { PRO } \\
\text { Productivity } \\
\text { or cognitive } \\
\text { performance }\end{array}$ & & $\begin{array}{l}\mathbf{C} \text { U } \\
\text { cial Unspecified }\end{array}$ \\
\hline $\begin{array}{l}\text { Personal Wellbeing } \\
\text { Psychological States and } \\
\text { Traits }\end{array}$ & & & & 1 & & & & & 1 \\
\hline Satisfaction & & & 1 & & & & & & \\
\hline \multicolumn{10}{|l|}{ Thatcher \& Milner (2014) } \\
\hline Satisfaction & & & 1 & & & & & & \\
\hline Absenteeism & & & & & 1 & & & & \\
\hline $\begin{array}{l}\text { Affect } \\
\text { Building Design and } \\
\text { Facilities }\end{array}$ & 1 & & 1 & & & & & & \\
\hline Other & & 1 & & & & & & & \\
\hline Presenteeism & & & & & 1 & & & & \\
\hline Productivity & & & & & & & 1 & & \\
\hline Sense of Inclusion & & & & & & & & 1 & 1 \\
\hline Sick Building Syndrome & & & & & & 1 & & & \\
\hline \multicolumn{10}{|l|}{ Torrington (2007) } \\
\hline $\begin{array}{l}\text { Affect } \\
\text { Building Design and } \\
\text { Facilities }\end{array}$ & 1 & & 1 & & & & & & \\
\hline Control & 1 & & & & & & & & \\
\hline Familial Context & & & & & & & & 1 & 1 \\
\hline Frailty, mobility and safety & & & & & & 1 & & & \\
\hline Other & 1 & 1 & & 1 & & & & & \\
\hline Participation and Interaction & & & & & & & & 1 & 1 \\
\hline Satisfaction & & & 1 & & & & & & \\
\hline Stress & & & & 1 & & & & & \\
\hline
\end{tabular}

Turunen et al. (2014)

Cognitive Performance

IIIness

1

Indoor Environmental Quality 1

Learning

Self-reported symptoms

Wellbeing

2

Wilson et al. (2014)

Building Design and

Facilities 
Table A -2. Wellbeing and buildings: Conceptual themes and subthemes used by the papers included in review.

\begin{tabular}{|c|c|c|c|c|c|c|c|c|}
\hline \multirow[b]{2}{*}{$\begin{array}{l}\text { PAPER CITATION / } \\
\text { CONCEPTUAL SUBTHEMES }\end{array}$} & \multicolumn{8}{|c|}{ Conceptual themes } \\
\hline & $\begin{array}{l}\text { ENV } \\
\text { Environmental } \\
\text { Quality, } \\
\text { Satisfaction } \\
\text { and/or Comfort }\end{array}$ & $\begin{array}{l}\text { EUD } \\
\text { Eudaimonic }\end{array}$ & $\begin{array}{l}\text { HED } \\
\text { Hedonic } \\
\text { or } \\
\text { Subjecti } \\
\text { ve }\end{array}$ & $\begin{array}{l}\text { MH } \\
\text { Mental } \\
\text { health } \\
\end{array}$ & $\begin{array}{l}\mathbf{0} \\
\text { Other }\end{array}$ & $\begin{array}{l}\text { PH } \\
\text { Physical } \\
\text { health }\end{array}$ & $\begin{array}{l}\text { PRO } \\
\text { Productivity } \\
\text { or cognitive } \\
\text { performance }\end{array}$ & $\begin{array}{l}\text { SOC U } \\
\text { Social Unspecified }\end{array}$ \\
\hline $\begin{array}{l}\text { Psychological States and } \\
\text { Traits }\end{array}$ & & & & 1 & & & & \\
\hline Self-reported symptoms & & & & & & 1 & & \\
\hline
\end{tabular}

Wu \& Noy (2010)

Indoor Environmental Quality 1

\begin{tabular}{lllllllllll} 
Grand Total & 37 & 7 & 21 & 15 & 7 & 25 & 14 & 21 & 3 \\
\hline \hline
\end{tabular}

